\title{
Supporting the development of scientific understanding when constructing an evolving explanation
}

\author{
Ann M. Novak ${ }^{1 *}$ (D) and David F. Treagust ${ }^{2}$ (D)
}

\begin{abstract}
We explore how students developed an integrated understanding of scientific ideas and how they applied their understandings in new situations. We examine the incremental development of 7th grade students' scientific ideas across four iterations of a scientific explanation related to a freshwater system. We demonstrate that knowing how to make use of scientific ideas to explain phenomena needs to be learned just as developing integrated understanding of scientific ideas needs to be learned. Students participated in an open-ended, long-term projectbased learning unit, constructing one explanation over time to address, "How healthy is our stream for freshwater organisms and how do our actions on land potentially impact the water quality of the stream?" The explanation developed over several weeks as new data were collected and analyzed. Students discussed evidence by revisiting scientific ideas and including new scientific ideas. This research investigates two questions: (1) As students engage in writing a scientific explanation over time, to what extent do they develop integrated understanding of appropriate scientific ideas? and (2) When writing about new evidence, do these earlier experiences of writing explanations enable students to make use of new scientific ideas in more sophisticated ways? In other words, do earlier experiences allow students to know how to make use of their ideas in these new situations? The results indicated statistically significant effects. Through various iterations of the explanation students included richer discussion using appropriate scientific ideas. Students were also able to make better use of new knowledge in new situations.
\end{abstract}

\section{Introduction}

As students explore a phenomenon, they need to gather evidence and use scientific ideas and reasoning to help them figure out and make sense of that phenomenon. One way to explain that phenomenon is by constructing a scientific explanation. Research shows that reasoning is the most difficult part of an explanation for middle school students (Berland \& Reiser, 2009; Gotwals \& Songer, 2006; NRC 2007; McNeill et al., 2006). To reason, students must have an understanding of scientific ideas; they should use these understandings to select certain data and then show why these data count as evidence and also support their claim. Recent research has shown that scientific

\footnotetext{
* Correspondence: anovak@greenhillsschool.org

${ }^{1}$ Greenhills School, Ann Arbor, Michigan, USA

Full list of author information is available at the end of the article
}

reasoning and domain-specific knowledge are significant predictors of experimental observation skills (Klemm et al., 2020). We argue that this scientific reasoning requires an integration of scientific ideas. Consequently, teachers should provide students with experiences that foster the development of integrated understanding of scientific ideas that are situated in real-world, meaningful contexts where students are required to apply their knowledge (Vallera \& Bodzin, 2020). What do these experiences look like and how can teachers best support students to develop integrated understanding of scientific ideas and to learn how to make use of those scientific ideas when explaining natural phenomena?

This research explored how students developed an integrated understanding of scientific ideas and used ideas to explain the health of a stream through constructing 
multiple iterations of an evidence-based scientific explanation over time. The explanation evolved over several weeks as students learned scientific ideas about four different water quality measures and collected and analyzed data from each of the water quality measures at different times. With each new added component of the water system, the overall context became richer. For the first two water quality measures of $\mathrm{pH}$ and temperature, students were guided to both include scientific ideas and how to use those ideas to explain the water phenomenon. Building from these experiences, more ideas were expected from students as they made sense of third and fourth water quality measures, namely, conductivity and dissolved oxygen. Although scaffolds were lessened, students were expected to develop more thorough explanations as they gained more knowledge and experience in writing scientific explanations.

\section{Theoretical framework for the study}

This study explores middle school students' development towards an integrated understanding of the health of a stream and how the learning environment and teacher support promoted this integrated understanding. The underlying theory for the work is that students experience learning in a particular context by exploring natural phenomena (National Research Council (NRC), 2012; National Academies of Sciences, Engineering, and Medicine (NASEM), 2019). This position is based on social constructivism (Vygotsky, 1986) where students actively engage with natural phenomena and collaborate with each other and the teacher to make sense of ideas; in so doing, the students construct an integrated understanding of the phenomenon. The learning environments for investigation should "relate to the interests and life experiences of students" (NRC. 2012, p. 31) and investigate phenomena that are "interesting and engaging to students (NASEM, 2019, p.4). As such, the learning environment explored in this study is situated in an authentic, real-world context.

Two major goals of science education focus on assisting students to explain various phenomena and to solve problems. Since scientists often construct evidencebased explanations for phenomena, students should also engage in the same activities of scientists. With new insights from research over the past two decades into how students learn and how to more effectively teach science, various documents have been published that use this growing body of research to assist teachers and curriculum designers. To best prepare the next generations of learners to explain scientific phenomena and to have the tools to use that knowledge to respond to challenging current and future problems that face our societies and our planet, the Framework for K-12 Science Education (NRC, 2012) proposed a new instructional approach.
This new approach, referred to as 3-Dimensional Learning, merges scientific and engineering practices (SEP), crosscutting concepts (CCC), and disciplinary core ideas (DCI). The study reported here applies this theoretical approach to instruction that incorporates the following concepts.

\section{The essential concepts incorporated in the study design}

For students to explain a complex phenomenon, they need to develop an integrated understanding of complex ideas that underpin the phenomenon. For this to be effective, teachers need to provide scaffolding, including timely and focused feedback, as support for students as they incorporate experimental evidence and scientific ideas into their explanations. Through these cycles of development and teacher feedback, students demonstrate integrated understandings of scientific ideas, the use of evidence, and the structure of explanations. Here, we discuss each of these concepts - integrated understanding, scientific explanations, evolving explanations, and scaffolds - that were incorporated in the research.

\section{Integrated understanding}

An expert in a particular field tends to possess rich, interconnected knowledge structures resulting in that individual having an integrated understanding of the disciplinary core ideas (DCI) of the phenomenon (Fortus and Krajcik, 2012; Hmelo-Silver, Pfeffer, 2004; Krajcik \& Mun, 2014; NRC 2008; Roseman, Linn, \& Koppal, 2008). Unfortunately, in many science classrooms, students often learn scientific ideas in isolation rather than through experiences that allow them to form connections among ideas. This lack of connection results in students not using their scientific ideas within the available scientific practices and necessary crosscutting concepts to make sense of a new phenomenon (NRC, 2012). Two more reasons contributing to a lack of connections among scientific ideas are when understanding is neither developed across time nor in context. Furthermore, in many classrooms, scientific ideas are not used to explain phenomena and especially so in more than one situation. As a result, students struggle to organize ideas because they lack experiences to form connected ideas and only possess disconnected information (Fortus \& Krajcik, 2012; Krajcik and Czerniak, 2018; NRC, 2000). We use the term "integrated understanding" to refer to a high level of connectedness and the identification of meaningful relationships between scientific ideas (Fortus \& Krajcik, 2012; Roseman et al., 2008).

Scientists not only have integrated understanding of important scientific ideas, but they also know how to use their understandings to make sense of and develop explanations of phenomena with high levels of sophistication (Hmelo-Silver \& Pfeffer, 2004; Rottman, Gentner 
\& Goldwater, 2012). Because scientists have integrated understanding as well as experiences where they have made use of those understandings, they are able to use their understandings of DCIs and apply scientific practices and crosscutting concepts to new situations. Using understandings in new situations is an outcome of classroom science teaching expected by the NRC (2012); the Framework for K-12 Science Education in the United States (NRC 2012a), as well as policy documents from other countries (Finnish National Board of Education, 2015; Kulgemeyer \& Schecker, 2014; OECD, 2016). These documents call for students to actively use their knowledge to explain phenomena and solve problems and to take what they have learned in one context and apply it to new contexts.

Fully explaining scientific phenomena necessitates that students understand a complexity of scientific ideas and connections between those ideas and know how to use those understandings in new situations to justify claims and make sense of evidence. Because students' ideas are often fragmented (NRC, 2000), it is not surprising that students find it challenging to make sense of phenomena, solve challenging problems, or use their learning in new situations (Bransford \& Schwartz, 1999).

In the era of three-dimensional learning stressing that students use their knowledge (NGSS 2013; NRC 2012a; NRC, 2012b), classroom instruction should guide students towards making connections among scientific ideas in tandem with learning how to make use of those scientific ideas in new situations. These ideas are supported by the work of Zimmerman (2000) which asserts the importance of teaching scientific content simultaneously with "experimentation and evidence evaluation skills" to help students better understand science (p.140). Pelligrino and Hilton (2012) state that designing classroom instruction that provides students with experiences that require them to use their knowledge is both an opportunity and challenge that needs substantial attention by the research community.

\section{Scientific explanations}

Assisting students to use their understanding of science ideas, not just to "know" science ideas, is a challenge identified in the research (NRC, 2012b). How can students be supported in developing an integrated understanding of scientific ideas that they can apply to solve problems and make sense of phenomena? In this study we focus on this challenge. One way to address this challenge is to provide students with an instructional context where they are supported to develop evidence-based explanations that use scientific ideas to justify why their evidence supports their claims.
Constructing evidence-based explanations in science classrooms is emphasized in major science education documents (NASEM, 2019; NGSS, 2013; NRC 2007, 2012a; OECD, 2016). When developing learning experiences for students, the three dimensions - scientific and engineering practices (SEP), crosscutting concepts $(\mathrm{CCC})$, and disciplinary core ideas (DCI). - need to work together; "Helping students learn disciplinary core ideas through engaging in scientific practices will enable them to become less like novices and more like experts" (NRC, 2012, p. 25). One such scientific practice - constructing explanations of phenomena - may assist students to move from understanding scientific ideas as disconnected facts to begin to organize their knowledge around core scientific ideas in much the same way that experts do. Kulgemayer (2018) describes an effective instructional framework for explanations construction in science teaching which includes involvement of the learner.

Supporting middle school students in the practice of constructing explanations is challenging. An explanation framework comprised of three components - claim, evidence, and reasoning - can assist students in constructing explanations (McNeil \& Krajcik, 2011). Students need opportunities to make claims based on available evidence and use scientific ideas to justify why the evidence supports the claim. They also need support, not only to understand that they need to include scientific ideas, but how to incorporate the ideas. The level of sophistication of students' explanations will, in part, determine if learners develop integrated understanding (Fortus \& Krajcik, 2012; Hmelo-Silver, Pfeffer, 2004; NRC 2008; Roseman, Linn, \& Koppal, 2008). Fewer connections of scientific ideas will result in less sophisticated responses. Three-dimensional learning environments (NGSS, 2013; NRC, 2012a) that engage students in making sense of a phenomenon (or designing solutions to problems) where students have to use all three dimensions - disciplinary core ideas, crosscutting concepts, and scientific practices to construct explanations - can help students make connections among ideas that broaden and deepen their levels of scientific knowledge. These environments also provide students with experiences of how to make use of their knowledge (Krajcik \& Shin, 2014; Linn \& Elyon, 2011; NRC, 2012a).

\section{Evolving explanations}

The most frequently described situations in the science education literature related to students constructing explanations are when students write several distinct, short explanations, typically a paragraph or two, throughout a unit (Cavagnetto, 2010). These explanations are based on evidence from different experiments that investigate different phenomena but relate to similar scientific ideas. 
In contrast, in the research reported here, we explore students' construction of one explanation over a period of time as more evidence is collected related to one, complex phenomenon comprised of multiple subcomponents. The various iterations of the explanation can become conceptually richer as students gain experience with using scientific ideas as well as with writing explanations. An evolving explanation is the term used to describe such multiple iterations of an explanation that is constructed over time (Novak \& Treagust, 2018). Complex phenomena, such as a freshwater system, cannot be explored and explained in a short period of time. We have found no other studies in the literature that investigate this type of explanation. Gerard, Kidron \& Linn (2019) and Lee, Pallant, Pryputniewicz, Lord, Mulholland, \& Liu (2019) used automated text scoring to support students in constructing and revising multiple explanations, typically around a paragraph, as part of shorter, 5-8 days units. Because the study reported here investigates longer and more complex evolving explanations, it is different from these studies.

\section{Scaffolds}

Scaffolds allow students to undertake tasks that they simply would not be able to do on their own (NRC, 2000; Quintana, Reiser, Davis, Krajcik, Fretz, Duncan, Kyza, Edelson, \& Soloway, 2004; Tabak, 2004; Wood, Bruner, \& Ross, 1976). Scaffolds assist learners not only to accomplish complex tasks but also to learn from those tasks. Providing a variety of scaffolds offers even more support by providing different means to develop ways of knowing, doing, and communicating. The explanation framework (McNeil \& Krajcik, 2011), along with other teacher scaffolds, assists students because it provides an accessible structure (McNeill \& Krajcik, 2009; McNeill et al., 2006; Tabak, 2004). Similarly, The Explanation Tool framework (Windschitl \& Braaten, 2011) helped make explanations clear to novice teachers. Prompts helped students describe "what" happened and explained "how" and "why" things happened. The Explanation Tool also helped novice teachers focus on the core ideas of science (Braaten \& Windschitl, 2011). Using various teacher supports with other scaffolds can become synergistic; the scaffolds work together to support students in building understanding (McNeill \& Krajcik, 2009; Tabak, 2004). Feedback and multiple opportunities are also important scaffolds.

\section{Cycles of development and feedback - the importance of an iterative approach}

Learning complex ideas requires time (Krajcik \& Shin, 2021; NRC 2000; 2007), feedback (NRC, 2001), and opportunities for multiple exposures (NASEM, 2019).
Writing scientific explanations, particularly incorporating scientific ideas as part of reasoning, is a complex undertaking that requires time and feedback. The importance of developing learning materials with an iterative rather than sequential focus over time is paramount in helping students develop integrated understanding of scientific ideas, practices, and crosscutting concepts (Fortus and Krajcik, 2012; Nelson \& Hammerman, 1996; NRC, 2000, 2013). Revisiting ideas and building on those ideas over time can move students from understanding scientific ideas as unconnected facts towards building connections with relationships among ideas that leads to integrated understandings. Such connections promote further development of organized knowledge structures around core scientific ideas. In addition, if students explore different facets of a complex phenomenon that include new scientific ideas and collect and analyze these new data, students can make connections to their prior experiences which may provide them with a structure for building integrated understanding of new scientific ideas.

In this study, students developed and revised an explanation over a period of time as new evidence was gathered in an authentic context. The students expanded and revised their explanation as more data were obtained which provided them with a more comprehensive picture of the phenomenon. Such an iterative construction of an explanation over time allows students to rethink and revise their ideas (Novak \& Treagust, 2018) that includes practice and feedback (Black, 2003; Krajcik \& Czerniak, 2018; NRC, 2000; NRC, 2001). Moreover, when writing about new data that requires students to use new scientific ideas to explain how evidence support claims, the earlier experiences have the potential to provide students with knowledge of how to use those new ideas. These experiences may assist students to more thoughtfully undergo analysis of their results, by incorporating new scientific ideas in more complex ways when writing about new evidence.

The instructional materials in this study place students in a context where 1) previous ideas are revisited and built upon and 2) new ideas are introduced and incorporated. We argue that students' scientific understandings build progressively over time, and their understanding of scientific ideas is an emergent process. We also argue that understanding of and use of science and engineering practices is an emergent process and is not developed with single exposures. Consequently, teachers need to provide students with multiple opportunities to show their understandings (NASEM, 2019). The same skills should be utilized multiple times across a series of tasks (Bransford et al., 2000). The Framework (2012a) replaces skills with practices "to emphasize that using scientific investigation requires not only skill but also knowledge 
that is specific to each practice (p.30). For students to explain phenomena they need to develop strong understandings of scientific ideas integrated with the practice of developing a scientific explanation with multiple opportunities to use the practice and corresponding disciplinary core ideas. This process exemplifies knowledge-inuse, illustrating that content and practice are explicitly linked (NRC, 2012a). In addition, integrating crosscutting concepts such as cause and effect and systems with practices and content are essential to fully understand and explain phenomena.

Feedback is important for students to develop understanding of scientific ideas and how to use those ideas to explain phenomena (NRC, 2001). Practice and feedback work together to develop skill and expertise (Pellegrino et al., 2001). Feedback prompts students to consider new ideas, to expand their current thinking, to make connections between ideas, and to reconsider current thinking that may be inconsistent with their data or inconsistent with what scientists believe and also prompts students to adjust their claims (Novak \& Treagust, 2018).

\section{Methodology}

\section{Research context}

The phenomenon under study, the health of a stream for aquatic organisms, is a complex system with many components, or sub-systems, that are explored over time. During the investigation, additional water quality measures are sequentially introduced. The research reported first examines the incremental development of 7th grade students' scientific ideas; these ideas came from separate water quality measures across the various iterations of an evolving scientific explanation. We explored how students make use of scientific ideas in different situations - in this case using scientific ideas from different water quality measures as part of a scientific explanation. To make claims supported by evidence that can be justified with scientific ideas, students need to understand new scientific ideas and incorporate them into their own scientific explanation.

\section{Research questions}

Consequently, two research questions guided the study:

1. As students engage in writing a scientific explanation over time, to what extent do they develop integrated understanding of appropriate scientific ideas?

2. When writing about new evidence, do these earlier experiences of writing explanations enable students to make use of new scientific ideas in more sophisticated ways?

\section{Research design and procedures}

This study utilized a repeated measures research design with students writing four iterations of one explanation during a semester project (Cohen, Manion \& Morrison, 2011; Creswell 2009); during the water quality data collection portion of the project, students expanded and revised their explanations over the course of six weeks as they collected new evidence. The scientific ideas, which students incorporated into their explanation during the various iterations of the evolving explanation, were used as the data source for addressing the research questions.

\section{Participants}

Sixty, 7th grade students, ages $12-13$ years from four classes at an independent middle school in a small to medium sized mid-western city in the USA, participated in the study. Thirty-one percent of students in the school self-identified as persons of color. The majority of students were from middle to upper-middle income families. Eighteen percent of the student body received need-based financial aid. Forty-five percent of the students were boys and $55 \%$ were girls. The middle school is part of a 6-12 grade school. One hundred percent of the students graduate from high school and $100 \%$ of the graduates attend college each year. Two students were dropped from the study due to long-term absences. In addition, seven different students were absent for at least one iteration of the explanation. When reporting data, therefore, the number of students ranged from 51 to 54 participants.

\section{Instructional context}

The unit in this study used a project-based science learning approach (Krajcik \& Czerniak, 2018, Novak \& Krajcik, 2019). Based on 3-dimensional learning, the unit integrates disciplinary core ideas, scientific and engineering practices, and crosscutting concepts as envisioned by the new Framework for K-12 Science Education (2012) and the NGSS (2013). Disciplinary core ideas related to water quality and human impacts on earth systems, the scientific practice of developing explanations, and the crosscutting concept of cause and effect provided the 3dimensional learning focus of the research presented in this article (see Appendix 1). The unit, which the first author developed and taught (Novak, 2019), works to contextualize learning by creating a meaningful learning environment situated in an authentic context that drives a need for learning. Working from students' everyday experiences with fresh water and with peoples' land-use practices and investigating the water quality of a stream, the project was designed to build and connect ideas across time. Prior to these lessons, students were introduced to the water study through several contextualizing activities, over the course of several weeks. These activities set a meaningful context and assisted students in the development of foundational scientific ideas related to watersheds and point and non-point source pollution. 
Students were placed in teams and assigned to a stream section where they, on separate occasions, collected four pieces of empirical data in real time. Students developed one explanation to address the questions, "How healthy is our stream for freshwater organisms?" and "How do our actions on land potentially impact the water quality of the stream?" (Novak, et al., 2006; Novak, 2019; Novak \& Krajcik, 2019). The explanation gradually developed over the course of about six weeks as more and more data were collected and analyzed. This additional data provided new evidence. Students learned more scientific ideas related to each new water quality measure through class activities, experiments, and background information. In each cycle of data collection and analysis, students took part in discourse, where they discussed the meaning of the data, made further sense of ideas, worked to clarify their understandings, and debated claims. Such discourse occurred in small groups and in class discussions.

\section{Teaching sequence}

The explanation framework of claim, evidence, and reasoning (McNeill \& Krajcik, 2011) was utilized to support students in constructing an explanation of the water quality of a local stream by using the results of the various water quality measures. The aim was to assist students in learning how to develop a sophisticated, evidence-based scientific explanation of the stream system phenomenon. As students developed their explanation over time, not only would they include more scientific ideas, but those ideas would also become more connected as they applied their understandings to explain the health of the stream. To reason about evidence one needs to make use of scientific ideas: what the water quality test was measuring, why results were obtained (causes), and what the results meant for the health of the stream (consequences), specifically the organisms that inhabited the stream. An integrated understanding, therefore, could develop concurrently.

Initially, students in this study were unfamiliar with writing explanations. The initial explanation (Ex1) took place after two separate data collection episodes where students collected $\mathrm{pH}$ and then temperature data. This explanation was written before students were introduced to the explanation framework. Water quality data from all groups was shared during a class discussion after each data collection episode with particular focus on identifying similarities and differences in the results. Using these two water quality measures, the students were individually asked based on what was known about the stream right now: "Write what you think a scientist would write to respond to the question: How healthy is the stream for freshwater organisms?"

\section{The explanation framework and other scaffolds}

The explanation framework was then introduced to students. In small groups, students collaborated on the completion of a teacher-scaffolded guide sheet designed to support them in the construction of their explanations. The guide sheet included prompts to assist students to consider various scientific ideas, including the purpose of conducting each water quality measure. In addition, students were asked to consider both causes for their results and effects (the consequences) that those results might have on organisms in the stream. Students also included whether the results indicated the stream's health as excellent, good, fair, or poor, based upon National Water Quality Standards (Stapp \& Mitchell, 1995). The guide sheet also provided students with a structure for writing the various components of an explanation. The teacher moved from group to group to assist students. A portion of the guide sheet shown in Table 1 shows the prompts for scientific ideas and two spaces, one for students to record their notes for $\mathrm{pH}$ and the other for temperature. The entire guide sheet may be found in Appendix 2: Explanation Guide Sheet.

Students were instructed to use their guide sheet, which served as an outline, and to then individually revise their initial explanation (Ex1) with the expectation to include discussion of appropriate scientific ideas as part of their reasoning. This second iteration became Explanation 2 (Ex2). The teacher then provided students with written feedback that included, among other aspects, comments related to students' use of scientific ideas in their reasoning.

After completing Explanation 2 (Ex2) students were introduced to a third water quality measure, the amount of dissolved solids (measured using a conductivity probe). Following various lessons related to dissolved solids, student groups next collected this third piece of

Table 1 Portion of an Explanation Guide Sheet for Student Notes

REASONING: explain and discuss

results:

Use scientific concepts

from background information

with your evidence (Test

results and physical data)

What do the results Mean? Standard.

Are these results positive

Or negative? Why? consequences

from background (examples)

Why did you get these results?

Incorporate the causes completely discuss/explain-

Use info. From p.19 \& p.8

(hand-outs)

Is there another possible

Cause or consequence that you didn't

Use to explain? What is it? Why

Didn't you choose it (them?)? 
data, conductivity. This water quality measure included new scientific ideas unrelated to scientific ideas of $\mathrm{pH}$ and temperature. Data from each group were shared and discussed with the entire class. Student groups completed another less-scaffolded guide sheet to support them in continuing to develop their explanation, now based on three pieces of evidence. Students used these notes to add conductivity to their explanations. This iteration became Explanation 3 (Ex3). Additionally, students were to incorporate teacher feedback from Explanation 2 into this version. This task was followed by another iteration of teacher feedback, now related to $\mathrm{pH}$, temperature, and conductivity measures. A fourth piece of data, dissolved oxygen, that also included new scientific ideas, was collected following various lessons and the same cycle occurred: students shared data in class, student groups discussed and analyzed data while taking notes, and students individually incorporated the new data into their existing explanations. This final iteration of the explanation was Explanation 4 (Ex4). After each data collection and analysis, students were expected to include discussion of appropriate scientific ideas, which often was related to causes and effects, as part of their reasoning. Students were also expected to incorporate teacher feedback. The various iterations of the explanation are summarized in Table 2.

At the completion of the water unit, students had constructed an explanation of the complex stream phenomenon that included evidence from the four water quality measures: $\mathrm{pH}$, temperature, conductivity (dissolved solids), and dissolved oxygen.

\section{Data sources}

Each of four iterations of the evolving explanation for all students was collected (See Table 2). These iterations were: Explanation 1 (Ex1) written before the explanation framework was introduced that included $\mathrm{pH}$ and temperature measures; Explanation 2 (Ex2) after the introduction of the explanation framework that included $\mathrm{pH}$ and temperature; Explanation 3 (Ex3) that included $\mathrm{pH}$, temperature, and conductivity; and Explanation 4 (Ex4) that included $\mathrm{pH}$, temperature, conductivity, and dissolved oxygen. Teacher feedback from Explanations $\# 2$ and \#3 was also collected.

\section{Data analysis}

A comprehensive concept map (Novak \& Gowin, 1984) that represented all of the scientific ideas for water quality and the relationships and appropriate connections between them was created by the first author. Separate portions of the concept map that corresponded to each of the water quality measures are found in Supplementary Information - one each for $\mathrm{pH}$, temperature, conductivity, and dissolved oxygen.

Three water ecology experts evaluated the concept map for scientific accuracy verifying that it contained all of the scientific ideas and accurate relationships between those ideas. Next, the concept map was used to create a detailed rubric using a base rubric for analyzing scientific explanations (McNeill \& Krajcik, 2011). In order to do this, concepts and their connections were translated into statements and became part of the rubric (see Fig. 1 for the $\mathrm{pH}$ portion of the concept map and Table 3 for the $\mathrm{pH}$ portion of the rubric). The water ecology experts also verified the rubric for scientific accuracy. The rubric reflected accurate scientific ideas and meaningful connections and could be used to infer student understanding of the ideas for the various water quality measures. Higher scores on the rubric were evidence of more integrated understanding of the scientific ideas. In addition to the scientific ideas and their relationships, the reasoning portion of the rubric included a section to record whether or not students connected their science understanding to their evidence. Reasoning requires discussion of appropriate scientific ideas. Examining the development of scientific ideas across time is the focus of this article; therefore, the reasoning portions of the rubric are not included here and are reported elsewhere (Novak, 2015). The pH portion of the concept map is illustrated in Fig. 1. The translation of those concepts into statements that became the $\mathrm{pH}$ portion of the rubric is shown in Table 3. Students' explanations were scored one point for each accurate idea. Ideas that were inaccurate or missing were scored as zero. As seen in the $\mathrm{pH}$ portion of the rubric (Table 3), the maximum number of possible points for $\mathrm{pH}$ was six.

This same process was used for developing rubrics for the temperature, conductivity, and dissolved oxygen water quality measures. In addition to reasoning, the

Table 2 Four iterations of an Explanation

\begin{tabular}{|c|c|}
\hline Explanation \#1 (Ex1) & - Initial pH and Temperature explanation: Before intro of explanation framework \\
\hline Explanation \#2 (Ex2) & $\begin{array}{l}\text { - Rewrite } \mathrm{pH} \text { and temperature explanation: After intro of explanation framework } \\
\text { - Teacher provides feedback on Explanation } \frac{2}{2}\end{array}$ \\
\hline Explanation \#3 (Ex3) & $\begin{array}{l}\text { - pH and temperature - revision from teacher feedback } \\
\text { - conductivity added - first time } \\
\text { - Teacher provides feedback on Explanation } 3\end{array}$ \\
\hline Explanation \#4 (Ex4) & $\begin{array}{l}\text { - pH, temperature, conductivity - with revision from teacher feedback } \\
\text { - dissolved oxygen added - first time }\end{array}$ \\
\hline
\end{tabular}




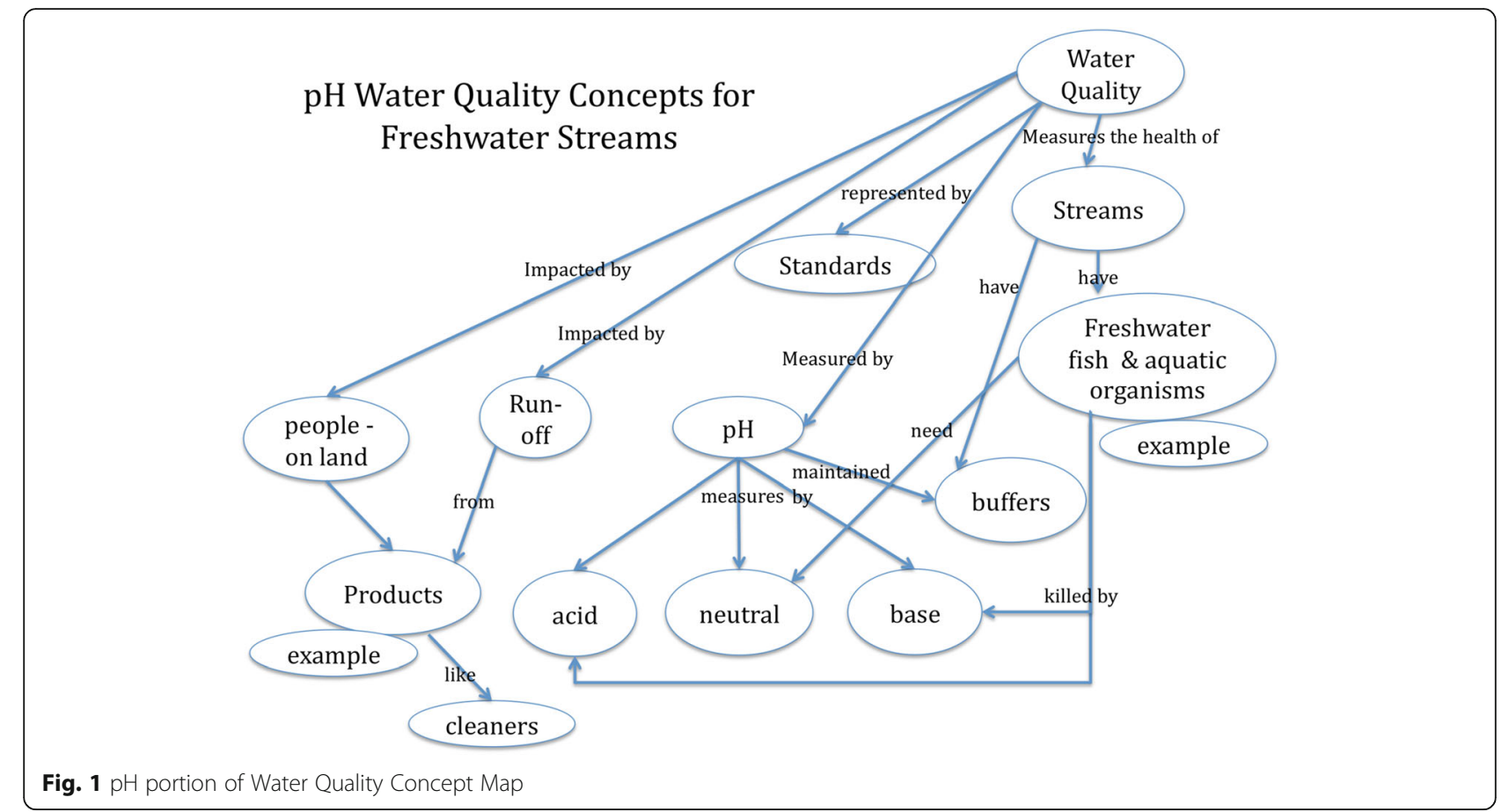

complete rubric included claim, evidence, rebuttal, and action steps in order to gain a more comprehensive insight into how students' explanations evolved over time. The rubric for Explanation \#4, which contains each of the four water quality measures, including all of the science ideas for each of the water quality measures, may be found in Appendix 3. The research reported here focuses on students' development and use of scientific ideas during the course of developing an explanation over various iterations.

For all iterations of the explanation, the students' scientific ideas were compiled for each water quality measure. In addition to the first author, two raters who were knowledgeable about the teaching unit and about

Table 3 Translation of pH concepts into statements that became the $\mathrm{pH}$ portion of the rubric

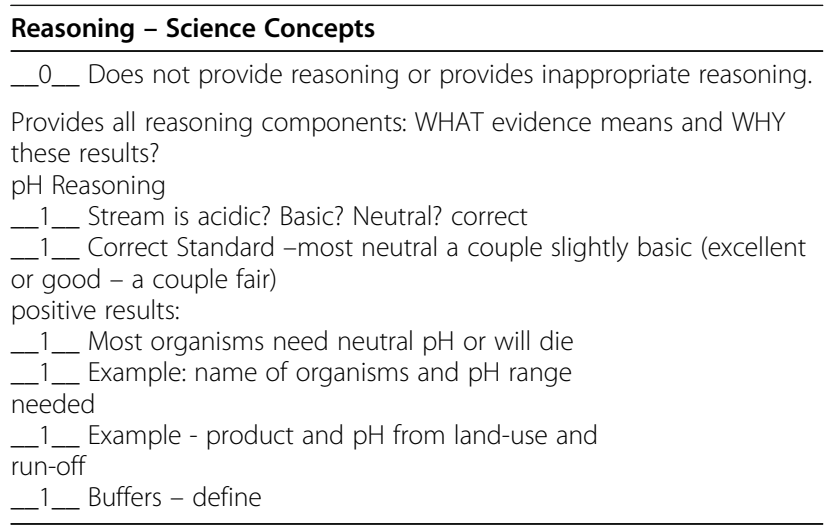

scientific explanations, and had been trained by the first author, scored a portion of students' explanations. As noted by McHugh (2012), statistics used to measure inter-rater and intra-rater reliability include "percent agreement, Cohen's kappa (for two raters), the Fleiss kappa (adaptation of Cohen's kappa for 3 or more raters) ..." . (p. 277). For this study, we used percent agreement because our situation was that "the [three] raters are well trained and there is little guessing, the researchers may safely rely on percent agreement to determine interrater reliability" (p. 282). The three raters each scored the four iterations of four different students totaling 16 explanations. An $88 \%$ inter-rater reliability was obtained. The first author scored the remainder of the other students' explanations. To check for "drift" in scoring, the other two scorers each scored four additional students (16 explanations) and those were set aside for later comparison. Half-way and three-fourths of the way through the scoring process, the researcher chose and scored two of these students and compared her scoring to the others scores to check for consistency. The inter-rater reliability remained consistent.

To answer Research Question 1: As students engage in writing an evolving scientific explanation over time, to what extent do they develop an integrated understanding of the scientific ideas about water quality?, student scores from the rubric were used to conduct a multivariate test of MANOVA with Wilks' lambda, the most appropriate statistic (Hinton, Brownlow \& McMurray, 2004, p. 231) using a repeated measure design for each 
separate water quality measure. Repeated measures were obtained for four iterations of $\mathrm{pH}$ and four iterations of temperature. In addition, repeated measures were obtained for two iterations of conductivity data (students did not include conductivity in the first two iterations). The conductivity measure had different scientific ideas than $\mathrm{pH}$ and temperature. Dissolved oxygen data was not included because it was part of the final water quality measure and did not undergo revision.

To answer Research Question 2: When writing about new evidence, do these earlier experiences of writing explanations enable students to make use of new scientific ideas in more sophisticated ways? a comparison of weighted mean scores from each water quality measure that was written by students for the first time was completed. Because there were different total possible points for each water quality measure, weighted scores were used to ensure equal value. This comparison allowed the researchers to determine if students analyzed and incorporated new scientific ideas when writing about new evidence.

\section{Results}

Research question 1: evolving explanation towards developing integrated understanding?

Research Question 1 explored students' development of a more integrated understanding of the scientific ideas about water quality across time as they wrote an evolving explanation. We start with an illustrative example that examines the progression of scientific ideas related to $\mathrm{pH}$ through each of the four iterations made by one student, Paul, who is representative of many students whose work fell in the middle to upper-middle ranges relative to his peers. This series of writing and analyses provides an example of the research procedure followed by the findings from the study.

\section{Incremental development of $\mathrm{pH}$ ideas across time: Paul's Ex1 to Ex4}

Paul's progression of $\mathrm{pH}$ ideas through the four iterations of his explanation are shown below. Included are his writing, how his writing would map onto the $\mathrm{pH}$ concept map, his rubric scores, and teacher feedback that he received which he was to incorporate in subsequent iterations. Portions of the writing that are accurate scientific ideas in the rubric are underlined. Vague or inaccurate concepts were scored as zeros.

Paul's Initial Explanation (Ex1) responding to the question, "What do you think a scientist would write about the health of the stream for freshwater organisms based on what we know now? included the following discussion about $\mathrm{pH}$ :
" $\mathrm{pH}$ is testing if our stream is acidic, basic, or neutral. This is done on a scale that goes from 0-14. Our stream is mainly from 6-8 on the scale. This means the water is in the neutral zone. Neutral is the area that can support every organism. This tells us that not many acidic or basic pollutants have entered our stream. If the stream is acidic or basic the water cannot support life and things begin to die."

Scientific ideas that Paul incorporated into his Initial Explanation (Ex1) are mapped onto the $\mathrm{pH}$ portion of the concept map in Fig. 2 (highlighted). Paul presents a few scientific ideas. He is missing many ideas as well as connections between the ideas. His initial explanation does not reflect integrated understanding of $\mathrm{pH}$ and water quality. Based on the rubric, Paul earned two out of the possible six points.

Following the introduction of the Explanation Framework, Paul revised his initial explanation and his $\mathrm{pH}$ portion looked like this:

" $\mathrm{pH}$ is testing if a substance is acidic, basic, or neutral. It goes on a scale that goes from 0-14. 6-8 is in the neutral zone. We choose three locations; $A, B$, and C. Location $A$ had a neutral pH of 7.5. Location $B$ had the same $p H$. Location $C$ had a little more acidic. It had a still neutral zone $p H$ of 6.5. All of our locations are in the excellent range of Water Quality Standards (6.5-7.5). As my graph says these are not harmful results. These results mean that all organisms are able to inhabit this area. They are positive and environmentally friendly results. If $\mathrm{pH}$ gets too acidic or basic it has the power to kill off the organisms. Fortunately we have a good result. There are no factories in the area dumping chemicals into the stream. We are also very protective of our storm drains at Greenhills. Earlier $7^{\text {th }}$ graders have put badges on them to emphasize the harm of dumping into the storm drains."

Accurate scientific ideas in the rubric are underlined. Figure 3 represents ideas that Paul incorporated into his revised explanation (Ex2) mapped onto the $\mathrm{pH}$ portion of the concept map that are added to his initial map. $\mathrm{He}$ includes additional scientific ideas as well as made connections between ideas. Based on the rubric, Paul now earned three out of the possible six points.

The teacher then provided feedback to Paul for Explanation 2 (Ex2):

In response to Paul's statement that "all organisms are able to inhabit this area" the teacher provided the following feedback:

Teacher comment: "Can you provide 2 specific examples from p.19 and the pH range they need to live?" 


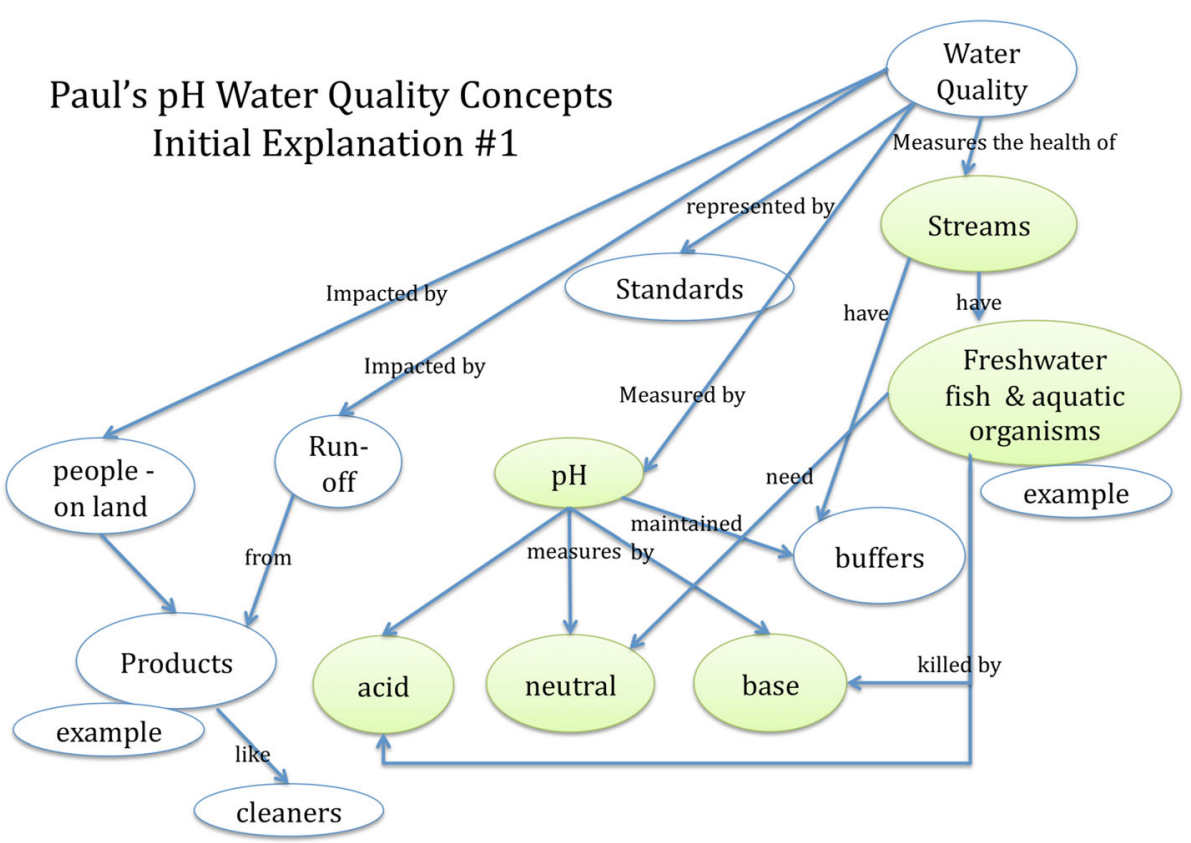

Fig. 2 Paul's Initial Explanation: Rubric Score - 2/6 points

In response to Paul's comment that 7th graders have put badges (permanent stickers that inform people, "Do not dump. Leads to rivers.") on storm drains:

Teacher comment: "Great - can you talk about what substances, and from where, could impact the stream's $p H$ - car products we tested etc. you reference dumping INTO storm drains - but people products can get into storm drains without direct dumping-discuss."
In response to Paul's statement that there are "no factories in the area dumping chemicals into the stream" the teacher gave the following feedback:

Teacher comment: "Good - another reason might be buffers - define/discuss".

Now, in Explanation 3, Paul incorporated teacher feedback from $\mathrm{pH}$ (and also temperature which is not illustrated here) as well as scientific ideas related to

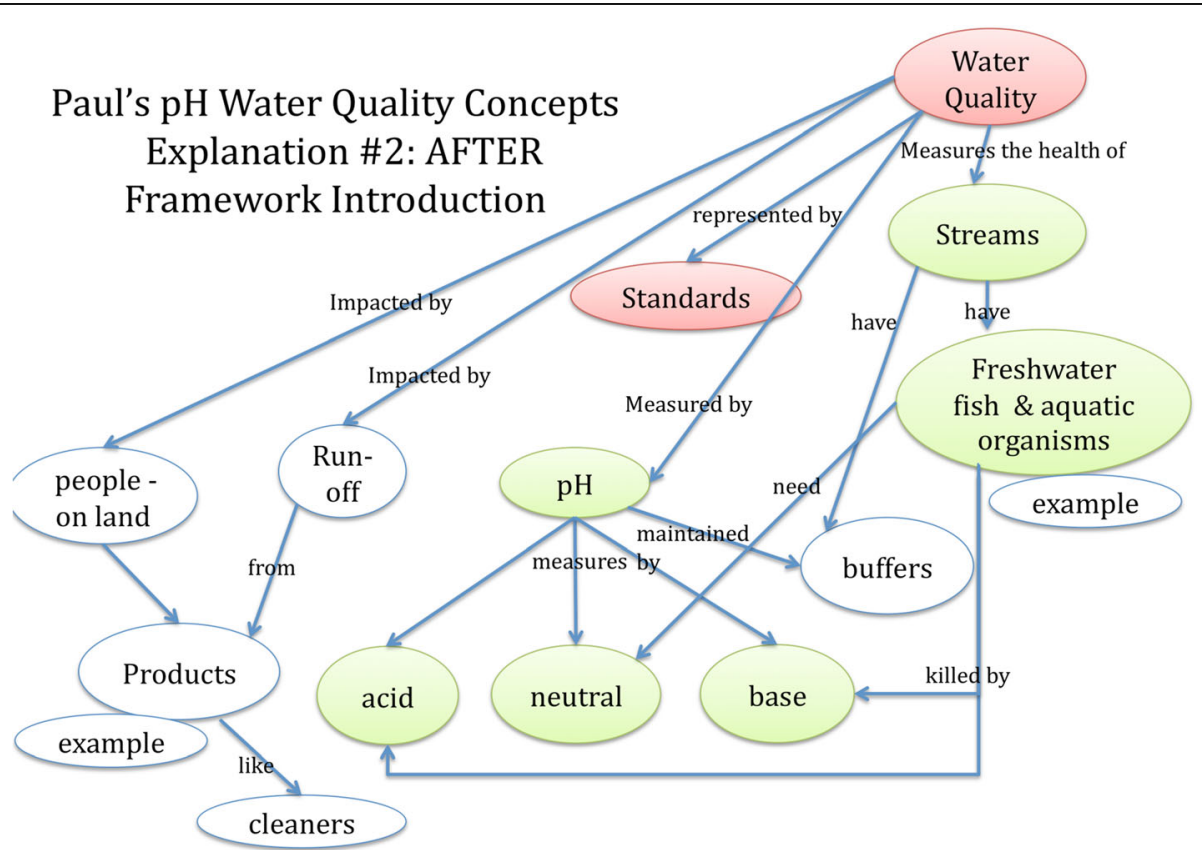

Fig. 3 Paul's Explanation 2 (Ex2): Rubric Score - 3/6 points 
conductivity, a third water quality measure for which students obtained data. Here is Paul's pH portion of Explanation 3 (Ex3) after receiving teacher feedback with accurate concepts underlined:

" $p H$ is testing if a substance is acidic, basic, or neutral. It goes on a scale that goes from 0 to 14. 6-8 is in the neutral zone. We choose three locations; $A, B$, and C. Location $A$ had a neutral $p H$ of 7.5. Location $B$ had the same $p H$. Location $C$ had a little more acidic. It had a still neutral zone $p H$ of 6.5. All of our locations are in the excellent range of Water Quality Standards (6.5-7.5). As my graph says these are not harmful results. The largest variety of animals can only live from 6.5-7.5. Snails, clams, and mussels live in 7-9. These results mean that all these organisms are able to inhabit this area.

If $\mathrm{pH}$ gets too acidic or basic it has the power to kill off the organisms. Fortunately we have a good result. There are no factories in the area dumping chemicals into the stream. Buffers also help the numbers. A buffer is a natural occurring chemical that helps maintain a neutral pH. The little pollution we get the buffer can take care of. We are also very protective of our storm drains at (our school). Storm drains are connected with non-point source pollution. Pollutants can get onto the streets, when it rains them downhill, this is called runoff. The pollutants get to the storm drains which leads the pollutants to the streams. Earlier 7 th graders have put badges on them to emphasize the harm of bad runoff into the storm drains. These chemicals include car oil and antifreeze from things like leaks from cars. There weren't very many bubbles, and they are an indicator of chemicals. From this there are little chemicals."

Mapping these additional ideas onto the $\mathrm{pH}$ concept map produces a more complete concept map (Fig. 4). Not only are more scientific ideas included, but those ideas are connected to other ideas, illustrating that Paul is developing a more integrated understanding of $\mathrm{pH}$ and water quality through the relationships his concept maps portray. Based on the rubric Paul now earned five out of the possible six points.

After completing this explanation, Paul received the following teacher feedback:

Teacher comment: "Car oil doesn't have a $p H$ " and "... .with a $p H$ of .....?"

in response to his statement:

"chemicals include car oil and antifreeze from things like leaks from cars."

Paul incorporated this feedback as well as scientific ideas related to dissolved oxygen, into the fourth and final iteration of his evolving explanation, Explanation 4 (Ex4). The following is the $\mathrm{pH}$ portion of Paul's explanation with accurate concepts underlined:

" $\mathrm{pH}$ or the potential of hydrogen is the testing if a substance is acidic, basic, or neutral. It goes on a

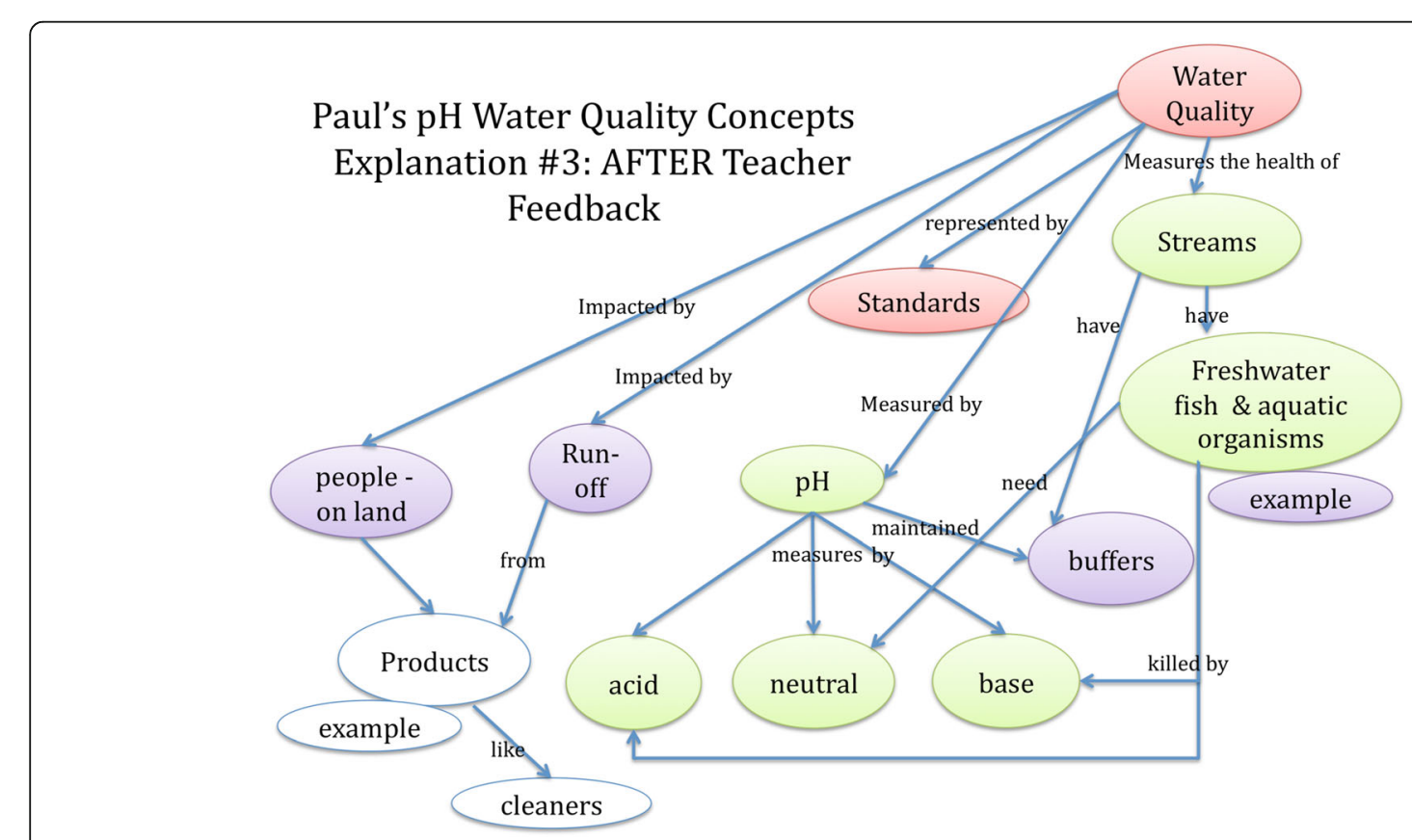

Fig. 4 Paul's Explanation 3 (Ex3): Rubric Score - 5/6 points 
scale that goes from 0-14. 6-8 is in the neutral zone. We choose three locations; $A, B$, and C. Location $A$ had a neutral $p H$ of 7.5. Location $B$ had the same $p H$. Location $C$ had a little more acidic. It had a still neutral zone $p H$ of 6.5. All of our locations are in the excellent range of Water Quality Standards (6.5-7.5). As my graph says these are not harmful results. The largest variety of animals can only live from 6.5-7.5. Snails, clams, and mussels live in 7-9. These results mean that all these organisms are able to inhabit this area. If $p H$ gets too acidic or basic it has the power to kill off the organisms. Fortunately we have a good result. There are no factories in the area dumping chemicals into the stream. Buffers also help the numbers. A buffer is a natural occurring chemical that helps maintain a neutral $p H$. The little pollution we get the buffer can take care of. We are also very protective of our storm drains at Greenhills. Storm drains are connected with nonpoint source pollution. Pollutants can get onto the streets, when it rains, they go downhill, this is called runoff. The pollutants get to the storm drains which leads the pollutants to the streams. Earlier $7^{\text {th }}$ graders have put badges on them to emphasize the harm of bad runoff into the storm drains. These chemicals include windshield wiper fluid that has a $\mathrm{pH}$ of 8.4. Another one is antifreeze which has a $\mathrm{pH}$ of 9.3. These chemicals come from things like leaks from cars. There weren't very many bubbles, and they are an indicator of chemicals. From this there are little chemicals."
Figure 5 illustrates the final $\mathrm{pH}$ concept map for Paul. It can be seen that Paul has now included all of the scientific ideas and showed the relationship between those ideas by accurately connecting them. Mapping Paul's ideas onto the concept map illustrates that he has integrated understanding of $\mathrm{pH}$ and water quality. Based on the rubric, Paul now earned all six possible points. Through the iterative process of the evolving explanation, we have tracked Paul's incremental development of $\mathrm{pH}$ ideas related to water quality of a freshwater system over time.

\section{Incremental development of ideas across time for all students}

Examining how all students' scientific ideas developed across the various iterations of the explanation, the results indicate that there is a statistically significant effect. Of the possible six points for $\mathrm{pH}$, the majority of student scores on the rubric from the initial explanation (Ex1) were zero, one, or two as seen on the left side of the chart in Fig. 6 that compares rubric scores from Explanations \#1 and \#4. For Explanation \#1 more than 50\% of students only included one scientific idea. Approximately one fifth of students included no scientific ideas. Explanation \#4 reflects a major shift in student scores with most students including many more scientific ideas, scoring five or all six points.

The results for the water quality measure of $\mathrm{pH}$ across the four iterations with the students who completed each explanation (see Table 4 and Fig. 7) show large effect sizes over the four iterations with statistically

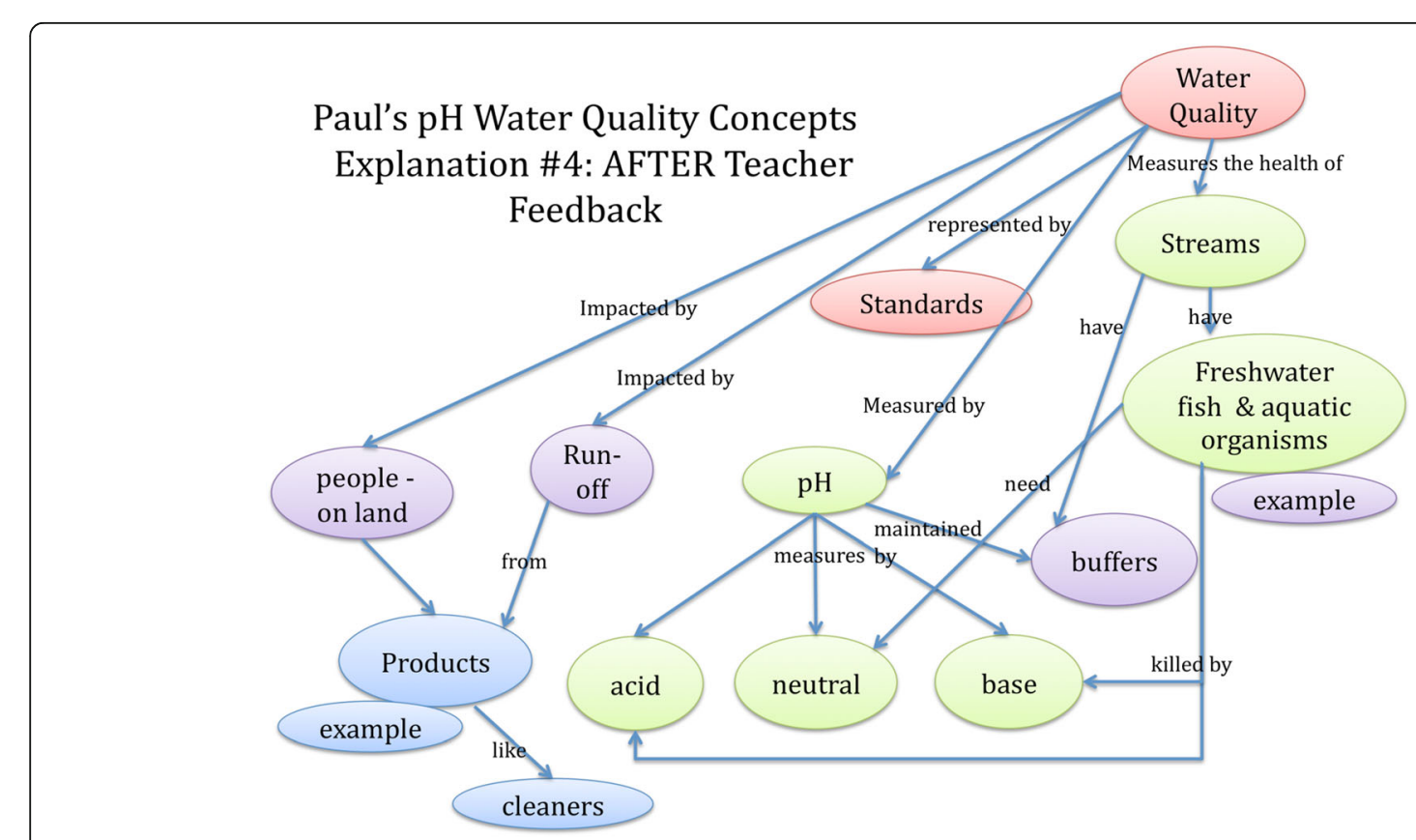

Fig. 5 Paul's Explanation 4 (Ex4): Rubric Score - 6/6 points 


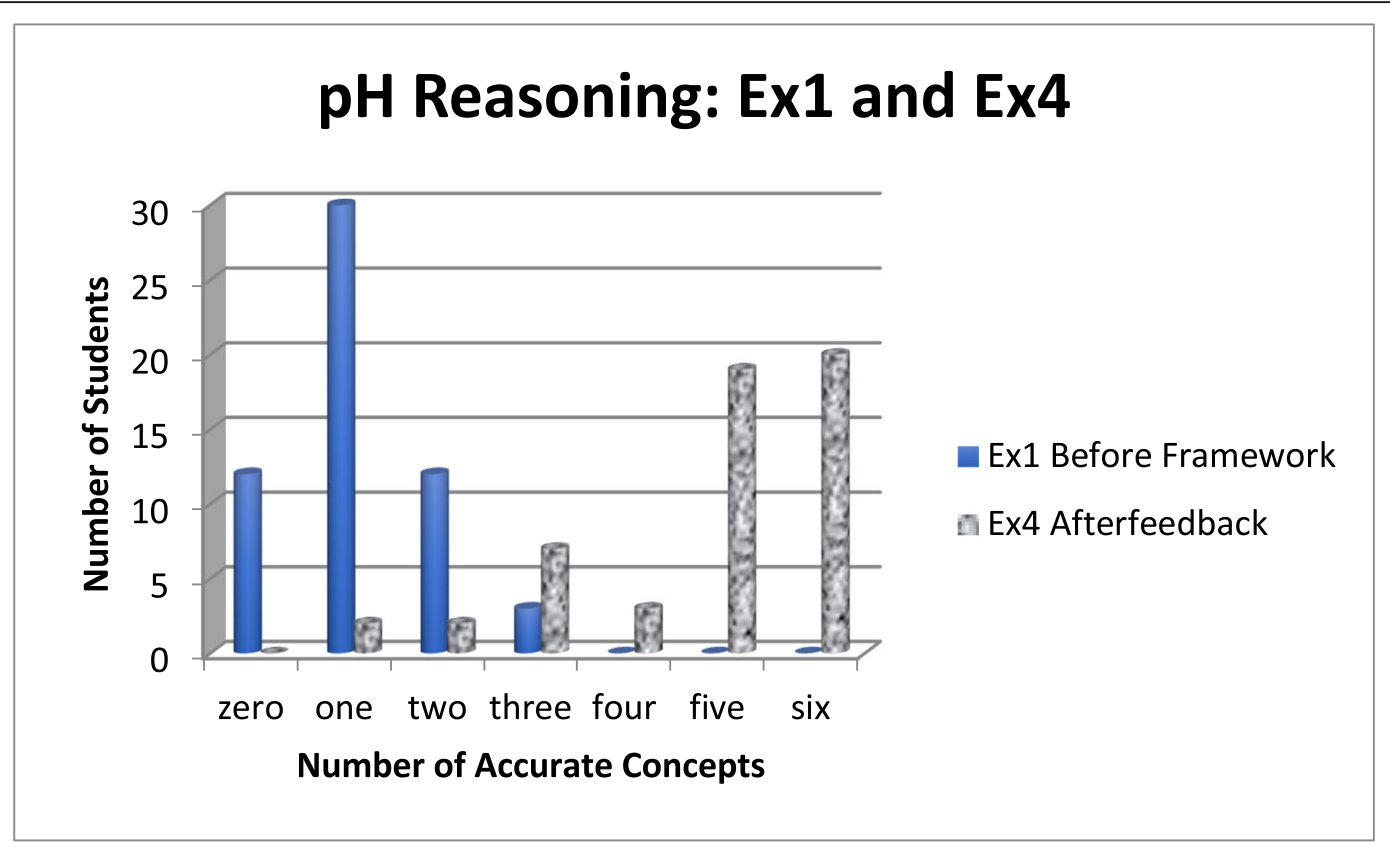

\section{Student Scores from the Rubric}

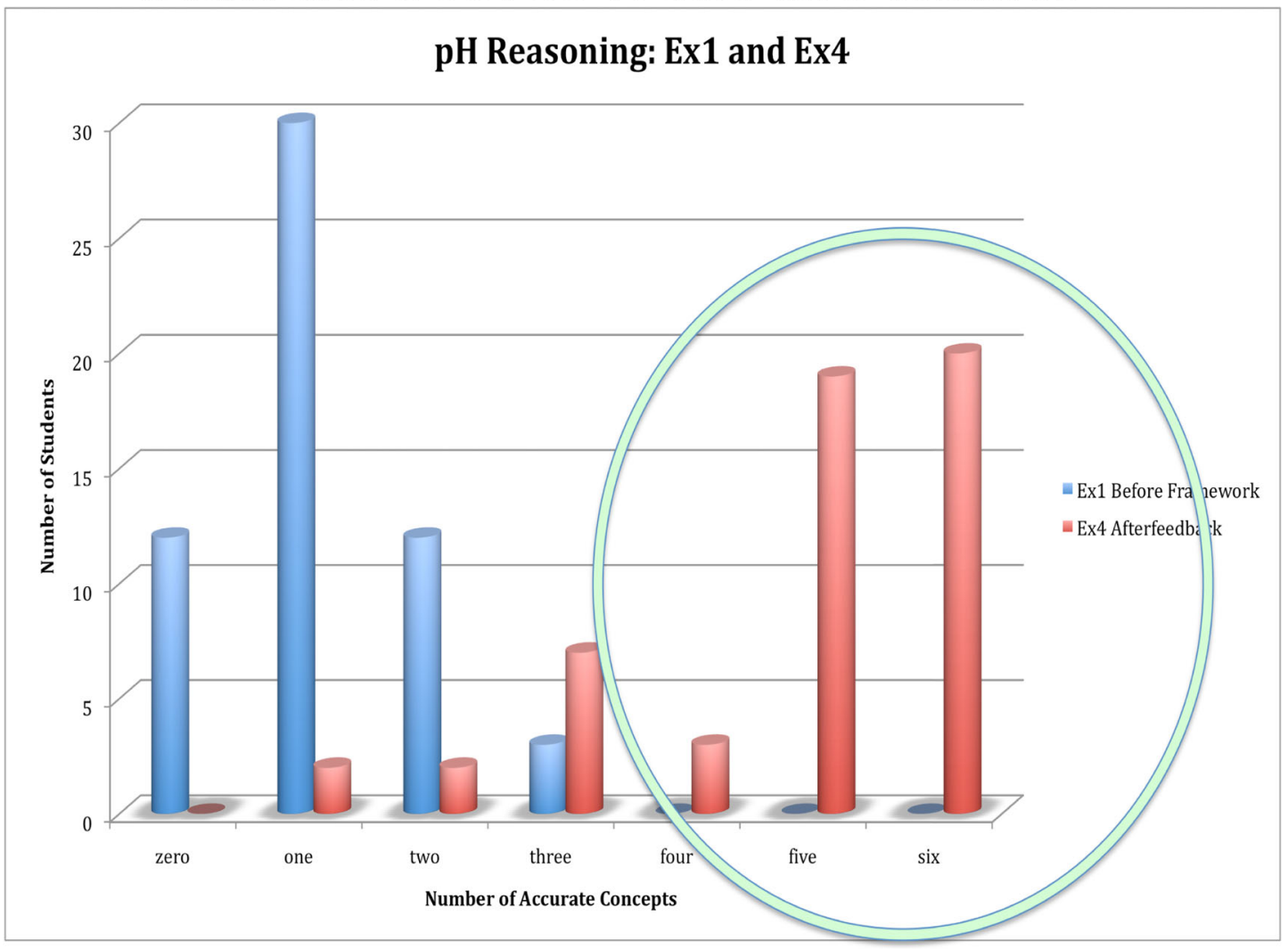

Fig. 6 Student Scores from Rubric: Initial Explanation (Ex1) compared to Final Explanation (EX4) 
Table 4 Students pH science ideas across an evolving explanation $(n=51)^{*}$

\begin{tabular}{lllll}
\hline & & Mean & SD & $\begin{array}{c}\text { Effect Size } \\
\text { Cohen's dav }\end{array}$ \\
\hline pH Ex1 & Before Explanation framework & 1.18 & .79 & 1.30 \\
pH Ex2 & After Explanation Framework & 2.51 & 1.59 & Ex1-Ex2: 1.27 \\
pH Ex3 & After Feedback & 4.08 & 1.40 & Ex2-Ex3: 1.08 \\
pH Ex4 & After Additional Feedback & 4.78 & & Ex3-Ex4: 0.47 \\
& Exp 4 compared to Exp 1 (before framework) & & Ex4-Ex1: 3.27 \\
& Exp 4 compared to Exp 2 (after framework) & & Ex4-Ex2: 1.16
\end{tabular}

*51 students completed all four iterations of the explanation that include $\mathrm{pH}$

significant differences in mean scores $(F=99.25$, effect sizes over the four iterations with statistically $p<.0001$; Wilks' Lambda $=.14$ ).

The results are similar for temperature. The development of scientific ideas associated with the temperature water quality measure across the four iterations with the students who completed each explanation (see Table 5 and Fig. 8) show, again, large significant differences (Wilks' Lambda $=.19 ; F=67.99$ $p<.0001)$.

Finally, conductivity results across iterations for Explanations \#3 and \#4 show a statistically significant difference (Table 6) as well $(F=35.34, p<.0001$; Wilks' Lambda $=.60$ ) with large effect sizes.

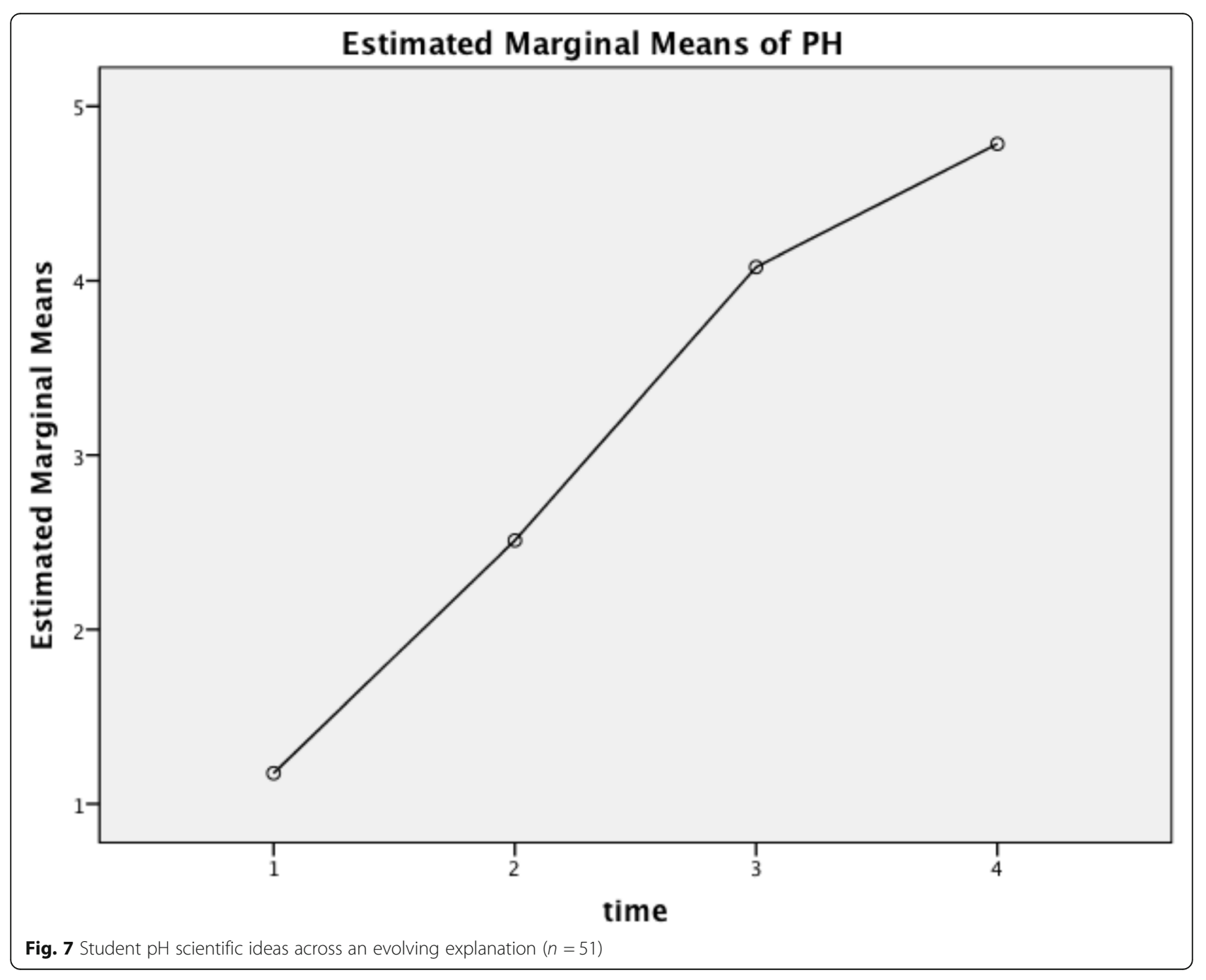


Table 5 Student Temperature science ideas across an evolving explanation $(n=51)^{*}$

\begin{tabular}{lllll}
\hline & & Mean & Std. Deviation & Effect size Cohen's dav \\
\hline Temp Ex1 & Before Explanation framework & 1.24 & .95 & \\
Temp Ex2 & After Explanation Framework & 3.27 & 2.09 & 1.34 \\
Temp Ex3 & After Feedback & 5.20 & 2.71 & 0.80 \\
Temp Ex4 & After Additional Feedback & 6.27 & 2.39 & 0.67 \\
& Exp 4 compared to Exp 1 (before framework) & & & Ex4-Ex1: 3.01 \\
& Exp 4 compared to Exp 2 (after framework) & & & Ex4-Ex2: 1.34 \\
\hline
\end{tabular}

*51 students completed all four iterations of the explanation that include temperature

Figures 6, 7 and 8 and Tables 4, 5 and 6 that show results from all students demonstrate that their scientific ideas shifted from disconnected ideas, if ideas were utilized at all, to highly connected organized knowledge structures (integrated understanding) across the four iterations of the explanation. Each iteration resulted in both more scientific ideas and more connections of the relationships between those ideas. Analysis for gender differences indicated no statistically significant differences $(p<.01)$ across the four water quality measures $(\mathrm{t}$ values ranged from .20 to .38 ).

\section{Research question 2: knowledge of how to make use of new scientific ideas in more sophisticated ways?}

This question explored whether or not students learned how to make use of scientific ideas that could then be applied in new situations, examining how students analyzed and incorporated new scientific ideas and relationships between ideas when showing how their evidence linked to claims. In other words, would students apply their earlier experiences to these new situations? Each water quality measure - $\mathrm{pH}$, temperature, conductivity, and dissolved oxygen - had distinctive scientific ideas. Students used $\mathrm{pH}$ and temperature scientific ideas both before and after knowledge of the Explanation Framework. Several weeks later, students' incorporated scientific ideas related to the conductivity water quality measure into their explanations. Dissolved oxygen ideas were added a couple of weeks after that (See Table 2). Therefore, additional water quality measures (conductivity and dissolved oxygen) were viewed as representing new situations. Scores from the first time that students wrote about $\mathrm{pH}$ and temperature ideas with knowledge of the explanation framework (Ex2) were compared with

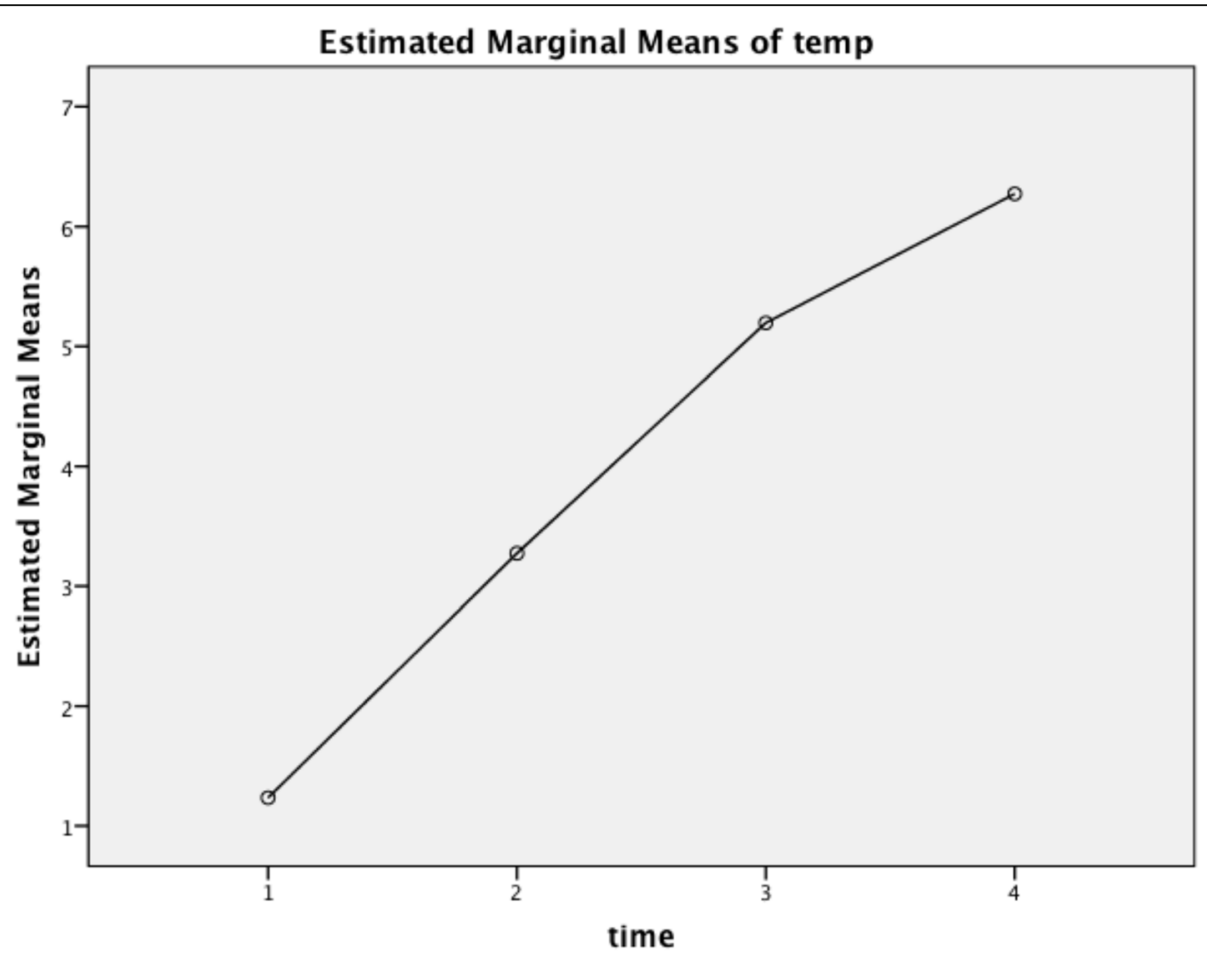

Fig. 8 Student Temperature Scores across Four Iterations of the Explanation 
Table 6 Student Conductivity science ideas across an evolving explanation ( $\left.n=54^{*}\right)$

\begin{tabular}{lllll}
\hline & & Mean & Std. Deviation & Effect size Cohen's dav \\
\hline Conductivity Ex3 & New Evidence & 4.19 & 2.08 & 1.77 \\
Conductivity Ex4 & After Feedback & 5.42 & 0.65 \\
\hline
\end{tabular}

*54 students completed iterations \#3 and \#4 that included conductivity

scores from the first time that students wrote about conductivity ideas (Ex3) and dissolved oxygen ideas (Ex4).

With regard to Paul's work, Fig. 9 illustrates the conductivity portion of the entire Water Quality Concept Map (Appendix 4) with Paul's initial scientific ideas related to conductivity mapped onto it. Paul's pH score for Explanation 2 (this was the first time writing about $\mathrm{pH}$ after being introduced to the explanation framework) was $3 / 6$ points (See Fig. 3), but his score was $6 / 7$ points for conductivity (conductivity has more scientific ideas and therefore was scored higher). Paul included many more scientific ideas the first time he wrote about conductivity compared to weeks earlier when writing about $\mathrm{pH}$. His initial ideas for conductivity were also more connected. He illustrated more integrated understanding of conductivity ideas when writing about them for the first time compared with his understanding of $\mathrm{pH}$ ideas. He was able to make much more use of scientific ideas in his first attempt to explain the conductivity measure's relationship to the water quality of the stream than in his first attempt to use scientific ideas to explain the $\mathrm{pH}$ of the stream and its relationship to the stream's water quality. Through earlier experiences, Paul learned that he needed to use scientific ideas when figuring out and explaining different components of the stream phenomenon.

To examine if all students' developed an understanding of how to make use of scientific ideas and apply them in new situations, the weighted mean reasoning scores for the first time students discussed scientific ideas from each water quality measure after they were knowledgeable in using the Explanation Framework were used (see Table 7). The weighted mean reasoning scores show that the explanations for the four water quality measures showed a large effect size and were statistically significantly different $(F=$ 17.83, $p<.0001$; Wilks' Lambda $=.48$ ). In fact, 18 students in the study earned $7 / 7$ points for their initial conductivity scores, and like Paul, 13 additional students scored $6 / 7$ points.

The first time that students included conductivity (the 3rd water quality measure) and dissolved oxygen ideas (the 4th water quality measure) into their explanations, the number of scientific ideas they included and the

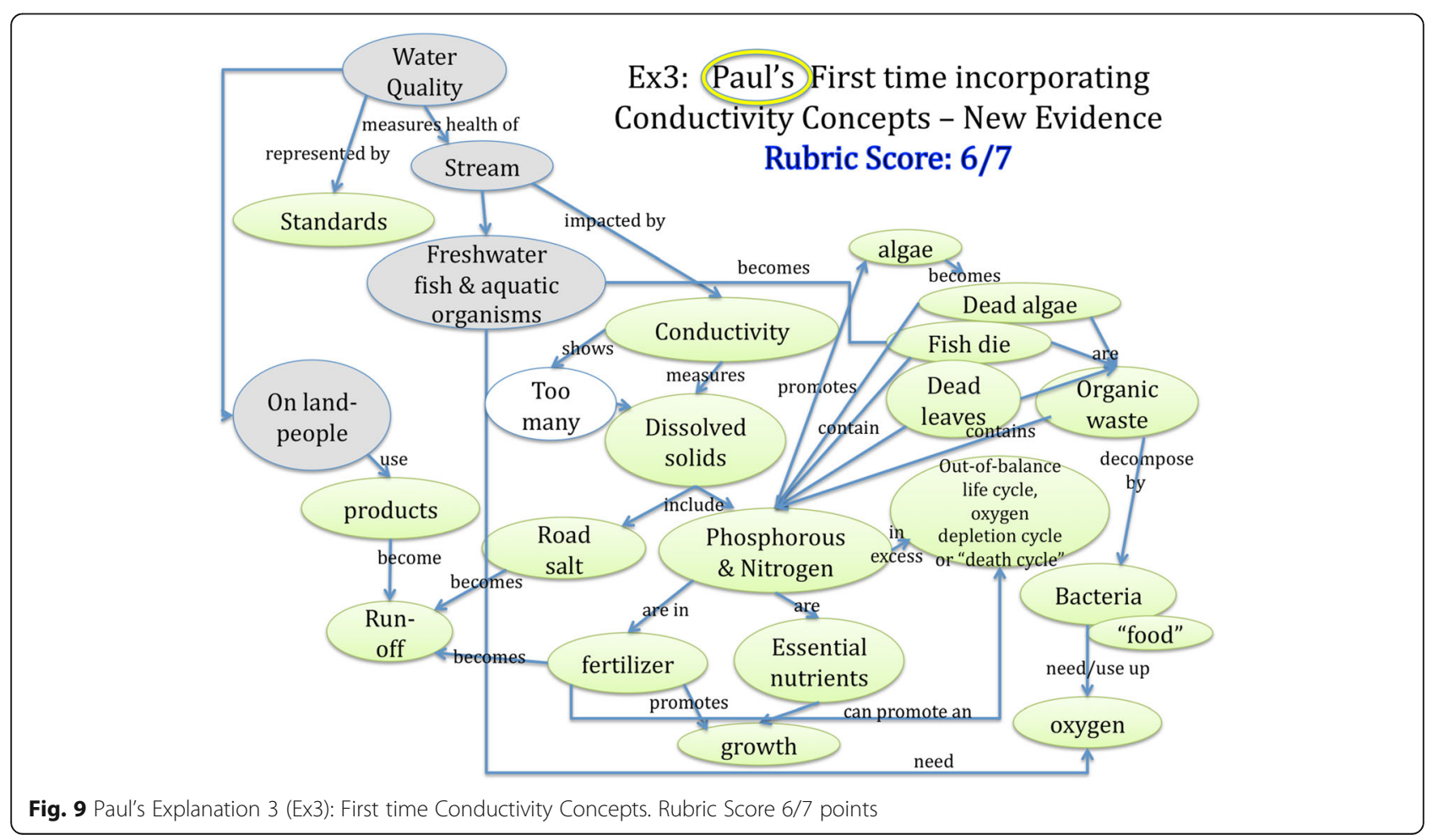


Table 7 Student Science Ideas - first time after introduction of Claim, Evidence, Reasoning $n=52$

\begin{tabular}{ll}
\hline Comparison: 1st time after Framework & $\begin{array}{l}\text { Effect size } \\
\text { Cohen's d }\end{array}$ \\
\hline pH Ex2 \& Conductivity Ex3 & 0.72 \\
pH Ex2 \& Dissolved oxygen Ex4 & 0.86 \\
Temperature Ex2 \& Conductivity Ex3 & 0.91 \\
Temperature Ex2 \& Diss Oxygen Ex4 & 1.08 \\
\hline
\end{tabular}

$\mathrm{pH}$ Ex2 \& Temp Ex2 done at the same time and therefore no compared

relationships between those ideas and were statistically significantly higher than the numbers included the first time students incorporated $\mathrm{pH}$ and temperature ideas (the first two water quality measures). All of these comparisons were made after the Explanation Framework was introduced. Figure 10 illustrates these differences.

The first two points on the graph are $\mathrm{pH}$ and Temperature, respectively. The third and fourth points are conductivity and dissolved oxygen, respectively. Data presented in Figs. 9 and 10 and in Table 7 provide evidence that engaging in a process of learning how to make use of scientific ideas (knowledge-in-use) through earlier water quality measures $(\mathrm{pH}$ and temperature) assisted students in making better use of new scientific ideas with later water quality measures (conductivity and dissolved oxygen). Students were able to apply their learning to new situations. The results indicate that knowing how to make use of scientific ideas to explain why evidence supports claims needs to be learned just as developing an integrated understanding of scientific ideas needs to be learned.

\section{Discussion}

Engaging students in situations where they must apply their understanding of scientific ideas to explain phenomena and/or solve problems is essential in helping students build an integrated understanding and apply those understandings in new situations. This is a major goal of science education worldwide (Finnish National Board of Education, 2015; Kulgemeyer \& Schecker, 2014; National Academies of Sciences Engineering and Medicine (2019); NRC, 2012a; NRC, 2012b; OECD, 2016). Not only does this mean that students need to develop integrated understanding of important scientific ideas, it also means that they need to know how to make use of their understandings. The research presented in this study provides evidence of an instructional context that helped students develop integrated understanding as they simultaneously applied those understandings to explain a phenomenon. The results demonstrate that knowing how to make use of scientific ideas to explain why evidence supports claims when explaining phenomena needs to be learned just as developing integrated understanding of scientific ideas needs to be learned. These findings provide support for the ideas that Pellegrino and Hilton (2012) put forth (2012) - the challenge in

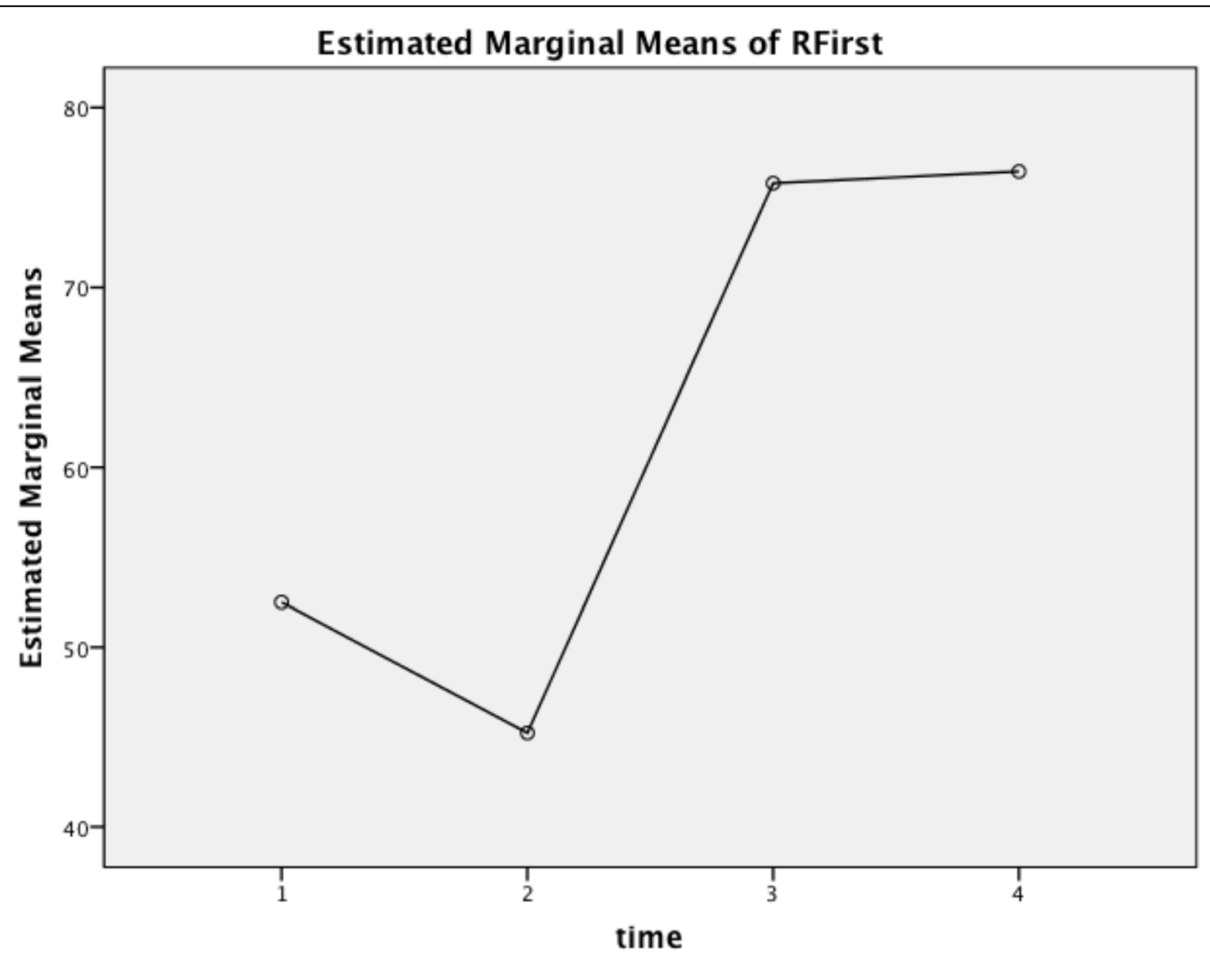

Fig. 10 Weighted Mean: First time incorporating scientific ideas for each water quality measure 
designing classroom instruction to assist students towards deeper learning to "know how, why, and when to apply knowledge ..." (p.6). Many documents call for students' learning experiences to integrate practices, crosscutting concepts, and core ideas (NAC, 2019; NGSS Lead States, 2013; NRC, 2012a). We also illustrate that the development of knowledge related to disciplinary core ideas in the study of water quality, scientific practices like constructing explanations, and crosscutting concepts like cause and effect, can occur concurrently and be supported through instruction. As such, this work provides evidence to support a 3-dimensional learning environment to promote understanding (NASEM, 2018). The findings from this study show that the iterative approach of the evolving explanation was instrumental in supporting student learning (Novak \& Treagust, 2018). One such finding apparent in the results showed that students were able to apply those understandings when explaining new evidence based on subsequent data collection cycles.

\section{More integrated understanding over time}

This study shows that, like experts (Chi et al., 1981; Fortus \& Krajcik, 2012; Hmelo-Silver \& Pheffer, 2004; NRC 2008; Roseman, Linn \& Koppal, 2018; Rottman et al., 2012), students can develop integrated understandings of scientific ideas and use those ideas to make sense of and explain phenomena. Students need understanding of scientific ideas in order to reason when they develop explanations of phenomena. Reasoning is found to be challenging for young learners (McNeill \& Krajcik, 2009). In order to reason, however, students must have an understanding of scientific ideas. Our findings indicate that students' ideas were initially underdeveloped; at the beginning of instruction students did not have well formulated ideas, but as time went on and as students continued to use those ideas our findings show that they built more integrated understanding.

Most research reports that students develop multiple explanations in a curriculum unit in order to explain different phenomena that focuses on the same scientific ideas (Cavagnetto, 2010). This work goes beyond the work of McNeill \& Krajcik (2009) and others (Cavagnetto, 2010) because of the iterative nature of constructing one evolving explanation. We found that utilizing an iterative approach, where students developed one expanding, an increasingly sophisticated explanation over time, assisted students to develop an integrated understanding of scientific ideas that can then be used to justify evidence and support claims in an explanation (Novak \& Treagust, 2018). Just like McNeill and Krajcik, (2009), Quintana et al., (2004), and Tabak (2004) we found that synergistic scaffolds worked together to support students to build understanding.
The results of this study in the context of an evolving explanation, are a unique contribution that can further develop the field of research related to the importance of engaging students in constructing explanations. The project-based unit in this study included several scaffolds: the Explanation Framework (McNeill \& Krajcik, 2011), classroom discussions, working with partners using scaffolded guide sheets, and feedback from the teacher (Pellegrino, Chedowsky \& Glaser, 2001). These scaffolds worked together to support students in their data collection, data analysis, and development of explanations. The substantial findings from this study indicate that when students' scientific understandings are progressively built over time, their use of appropriate scientific ideas increased significantly with each new experimental task and iteration of the explanation. Students were able to move away from underdeveloped ideas to make increasingly more connections among scientific ideas and build more meaningful relationships to develop more sophisticated understanding that moved toward integrated understanding (Roseman, Linn, \& Koppal, 2008). In other words, as students gained more experience in the practice of writing explanations, through a process of constructing an evolving explanation, and the synergy of various supports, they were able to present a richer discussion of appropriate scientific ideas. This pattern occurred for all of the water quality measures explored in this study.

Learning complex ideas take time. Like other researchers, we found that devoting time in the curricula where students work on meaningful tasks, in the form of iterative experiences (Fortus \& Krajcik, 2012) using supportive structures like the Explanation Framework, can assist students to think more deeply about scientific ideas. In this situation, students were synthesizing and using those ideas (Krajcik \& Shin, 2014) in the same way as professional scientists, making sense of data to explain a complex phenomenon. When students engaged in this iterative explanation their knowledge became more sophisticated; in other words, their ideas became more connected.

\section{Do iterative processes assist students to know how to use their learning in new situations?}

Perhaps the most substantial finding of this study is the comparison of students' work for each water quality measure the first time they wrote about scientific ideas related to that measure and after they were familiar with the Explanation Framework. As noted by Bransford and Schwartz (1999), students need opportunities to use their knowledge in new situations; this is exactly the situation presented to the students in this study. For example, the number of scientific ideas and connections when students included conductivity ideas (the 3rd 
water quality measure) and dissolved oxygen ideas (the 4th water quality measure) for the first time into their explanations were significantly higher than the number of scientific ideas and connections included the first time that students incorporated $\mathrm{pH}$ and temperature ${ }^{1}$ reasoning (the first two water quality measures). These results provide evidence that students learned how to make use of scientific ideas as part of an explanation of the phenomenon. This research presents an example of a context that allowed students to use knowledge by putting students in situations where they must use their understandings to explain a phenomenon and/or solve problems (NGSS 2013; NRC 2012; NRC, 2012b).

Assisting students to learn how to use their knowledge in new situations is a challenge. When students wrote about $\mathrm{pH}$ and temperature data (thermal pollution), they were novices in the practice of writing explanations. They also lacked connected scientific ideas and knowledge structures that prepared them to more fully utilize scientific ideas when incorporating new evidence and new scientific ideas into an existing explanation. The instructional context provided students with important experiences for analyzing and understanding new contexts. When analyzing and initially writing about conductivity data and later dissolved oxygen data, students were more familiar with the Explanation Framework; they had more experience and received teacher feedback related both to the framework and to scientific ideas related to $\mathrm{pH}$ and temperature water quality. When using $\mathrm{pH}$ and temperature for the first time, they had no conceptual "hooks" (or limited hooks) to understand the phenomenon. Consequently, writing about these two water quality measures was the start of students building integrated understanding around water quality. However, students were only beginning to develop integrated understanding for water quality because they also lacked experiences in making use of their knowledge. Our results show that once students had initial experiences and then included new evidence related to new scientific ideas, they incorporated appropriate and connected scientific ideas much more than they did in their earlier iterations of the explanation. These findings support the work of Bransford and Schwartz (1999). For conductivity and dissolved oxygen measures, students had a conceptual structure to which they could attach these ideas. The results suggest that students were able to apply their learning, related to explanations, in making use of more scientific ideas when using evidence to justify their claim, and how to think more deeply about scientific ideas by making connections among them, as they gained more experience (See Table 7).

${ }^{1}$ Explanation \#2, after the Explanation Framework was introduced, was used for the $\mathrm{pH}$ and temperature comparisons.
We interpret the results of this study to provide evidence that these middle level students were able to successfully develop scientific understanding about water quality measures, and through their experiences, use scientific ideas and justify the use of evidence. The students were able to use their learning in new situations because they developed a structure for thinking about and analyzing data as well as how to use scientific ideas. Consequently, it was easier for them to connect the new ideas to this structure.

\section{Implications for teaching}

Results from this study present several implications for instruction. First, this study provides an example of how teachers can use an evolving explanation to assist students in using science ideas to explain a complex phenomenon. Constructing an evolving explanation allows students to revisit science ideas and to build on those understandings. Constructing explanations is an important scientific practice that is seen multiple times throughout the New Framework for K-12 Science Education (2012) and other documents including, Ready, Set, Science, (National Research Council, NRC, 2008) Taking Science to School, (NRC 2007), How People Learn: Brain, Mind, Experience, and School (NRC, 2000), the National Science Education Standards (NRC 1996), the AAAS Project 2061 Benchmarks (1993), and Science for All Americans (1989). Constructing an explanation over time more closely mirrors the work of scientists. As such, a curriculum is needed where students engage in authentic, open-ended investigations. It is not enough for students to learn about science ideas. Students need to use ideas to make sense of phenomena to develop integrated understanding of science ideas, know how to make use of those ideas, and then apply those understandings in new situations.

A second implication for teaching is the importance of developing units and approaching instruction with the framework that enables students' understanding to develop over time. Just as with any new undertaking, students need multiple experiences that allow them to develop an understanding of practices and of the relationships between various scientific ideas (Fortus \& Krajcik 2011; NRC 2000, 2013; Nelson \& Hammerman, 1996) and of the relationships between various scientific ideas. In addition, students also need support in this challenging endeavor.

A related third implication is that teachers may see the value of developing curricular units similar to the organization of this healthy stream investigation where students explore a complex phenomenon that necessitates several cycles of data collection and analyses that they use to construct one overarching explanation, over time. The fourth implication for classroom practice is 
the development a set of teacher strategies and scaffolds to assist students throughout this process will be valuable for teachers and curriculum designers. Several teaching strategies and scaffolds were incorporated in this unit.

Finally, the process of developing students' explanations over a period time where new data are collected, analyzed and incorporated into a scientific explanation and where the teacher provides students with feedback and students revise their explanations, we demonstrate that knowing how to make use of scientific ideas to explain phenomena needs to be learned just as developing integrated understanding of scientific ideas needs to be learned. This study provides evidence that students used new science ideas to explain new evidence in much more sophisticated ways over time. The explanation framework, along with other scaffolds, can support all learners in this endeavor. Developing curriculum with evolving explanations provides students with a more authentic scientific experience that aligns with the Framework for K - 12 Science Education.

\section{Limitations of the study}

This study was based on a carefully constructed curricular unit that was enacted in four classrooms, with one teacher, and with a limited number of students. These are all limitations to the study. While the results of the study are promising, the next step is to examine this approach in other classroom situations.

\section{Conclusion}

The water quality of a stream to support life and the impact that human activity on the land can have on water quality presents an authentic and complex system that is framed by the theoretical framework that guided the study. To explore and explain this complex phenomenon requires extended time and multiple opportunities for learners to engage in using scientific ideas. The research reported here examined the development of students' scientific ideas across four iterations of an explanation that included four water quality measures explored in four separate episodes over a six-week period. For each water quality measure that was revised over time, students' understanding and use of the associated scientific ideas became more sophisticated, reflecting integrated understanding. As well, for water quality measures that were investigated later in the unit, students' use of these new scientific ideas to explain the phenomenon reflected stronger integrated understanding, showing that students prior experiences allowed them to know how to use scientific ideas when explaining phenomena. The significant learning gains exhibited by students in this study provide an example of how to: (1) assist students in the development of integrated understanding of scientific ideas, (2) aid them in learning how to use those understandings, and (3) apply their understandings in new situations. This study has demonstrated that developing the understanding of a complexity of scientific ideas and relationships between those ideas while also knowing how to use those understandings are two processes that are essential to explaining natural phenomena; these elements can develop concurrently through experiences provided to students during instruction.

\section{Supplementary Information}

The online version contains supplementary material available at https://doi. org/10.1186/s43031-021-00043-w.

Additional file 1. Appendix.

Acknowledgments

We are very grateful to Joe Krajcik for his insightful comments and invaluable feedback throughout the preparation of this manuscript. In addition, we thank Barb Ebeling for her thoughtful comments on reviewing the final article.

\section{Authors' contributions}

AN carried out the research, analyzed and interpreted the data, and wrote the manuscript. DT contributed to writing the manuscript and gave advice and editorial assistance. The authors read and approved the final manuscript.

Funding

Not applicable.

\section{Availability of data and materials}

The data used in the current study are available from the corresponding author upon reasonable request.

\section{Declarations}

Ethics approval and consent to participate

This study has been approved by the Curtin University Human Research Ethics Committee (Approval Number SMEC-99-11). All participants consented to participate.

Consent for publication

Not applicable.

\section{Competing interests}

The authors declare that they have no competing interests.

\section{Author details}

${ }^{1}$ Greenhills School, Ann Arbor, Michigan, USA. ${ }^{2}$ Curtin University, Perth, Australia.

Received: 15 July 2021 Accepted: 8 December 2021

Published online: 15 January 2022

\section{References}

Berland, L. K., \& Reiser, B. J. (2009). Making sense of argumentation and explanation. Science Education, 39(1), 26-55. https://doi.org/10.1002/sce.202 86.

Black, P. (2003). In The importance of everyday assessment, J. M. Atkins, \& J. E. Coffey (Eds.), Everyday assessment in the science classroom, (pp. 1-111). NSTA Press.

Braaten, M., \& Windschitl, M. (2011). Working toward a stronger conceptualization of scientific explanation for science education. Science education, 95(4), 639669. https://doi.org/10.1002/sce.20449.

Bransford, J.D., \& Schwartz, D.L. (1999). Rethinking transfer: A simple proposal with multiple implications. Review of Research in Education, 24, 61-100. https://doi.org/10.2307/1167267. 
Cavagnetto, A. R. (2010). Argument to foster scientific literacy: A review of argument interventions in $\mathrm{K}-12$ science contexts. Review of Educational Research, 80(3), 336-371. https://doi.org/10.3102/0034654310376953.

Chi, M. T. H., Feltovich, P. J., \& Glaser, R. (1981). Categorization and representation of physics problems by experts and novices. Cognitive Science, 5(2), 121-152. https://doi.org/10.1207/s15516709cog0502_2.

Cohen, L., Manion, L., \& Morrison, K. (2011). Research methods in education, (7th ed., ). New York: Routledge.

Creswell, J. W. (2009). Research design: qualitative, quantitative, and mixed methods approaches (3rd ed.). Thousand Oaks: Sage Publications.

Finnish National Board of Education (FNBE) (2015). National core curriculum for general upper secondary schools 2015. Helsinki, Finland: Finnish National Board of Education (FNBE) Retrieved from http://www.oph.fi/saadokset_ja_ohjeet/ opetussuunnitelmien_ja_tutkintojen_perusteet/lukiokoulutus/lops2016/103/ 0/lukion_opetussuunnitelman_perusteet_2015. Accessed 21 Nov 2021.

Fortus, D., \& Krajcik, J. S. (2012). In Curriculum coherence and learning progressions, B. Fraser, K. Tobin, \& C. McRobbie (Eds.), Second international handbook of science education, (vol. 52, pp. 783-798). Dordrecht: Springer. https://doi.org/10.1007/978-1-4020-9041-7.

Gerard, L., Kidron, A., \& Linn, M. C. (2019). Guiding collaborative revision of science explanations. International Journal of Computer-Supported Collaborative Learning, 14(3), 291-324. https://doi.org/10.1007/s11412-019-092 98-y.

Gotwals, A. \& Songer, N. (2006). Measuring students' scientific content and inquiry reasoning. In Barab, S. A., Hay, K. E., \& Hickey, D. T. (Eds.), The International Conference of the Learning Sciences: Indiana University 2006 Proceedings of ICLS 2006, Volume 1 (pp. 196-202). Bloomington, Indiana, USA: International Society of the Learning Sciences.

Hinton, P., McMurray, I., \& Brownlow, C. (2004). SPSS explained, (1st ed., ). London: Routledge. https://doi.org/10.4324/9780203642597.

Hmelo-Silver, C. E., \& Pfeffer, M. G. (2004). Comparing expert and novice understanding of a complex system from the perspective of structures, behaviors, and functions. Cognitive Science, 28(1), 127-138. https://doi.org/1 $0.1207 /$ s15516709cog2801_7.

Klemm, J., Flores, P., Sodian, B., \& Neuhaus, B. J. (2020). Scientific reasoning in biology - The impact of domain-general and domain-specific concepts on children's observation competency. Frontiers in Psychology, 11, 1050. https:// doi.org/10.3389/fpsyg.2020.01050.

Krajcik, J. S., \& Czerniak, C. (2018). Teaching science in elementary and middle school classrooms: A project-based learning approach, (5th ed., ). London. https://doi.org/10.4324/9781315205014.

Krajcik, J., \& Shin, N. (2014). Project-based learning. In R. Sawyer (Ed.), The Cambridge Handbook of the Learning Sciences (Cambridge Handbooks in Psychology, pp. 275-297). Cambridge: Cambridge University Press. https://doi. org/10.1017/CBO9781139519526.018.

Kulgemeyer, C. (2018). Towards a framework for effective instructional explanations in science teaching. Studies in Science Education, 54(2), 109-139. https://doi.org/10.1080/03057267.2018.1598054

Kulgemeyer, C., \& Schecker, H. (2014). Research on educational standards in German science education-Towards a model of student competences. EURASIA Journal of Mathematics, Science \& Technology Education, 10(4), 257269. https://doi.org/10.12973/eurasia.2014.1081a.

Lee, H. S., Pallant, A., Pryputniewicz, S., Lord, T., Mulholland, M., \& Liu, O. L. (2019). Automated text scoring and real-time adjustable feedback: Supporting revision of scientific arguments involving uncertainty. Science Education, 103(3), 590-622. https://doi.org/10.1002/sce.21504.

Linn, M. C., \& Elyon, B. S. (2011). Science learning and instruction: Taking advantage of technology to promote knowledge integration. Routledge. https://doi.org/1 $0.4324 / 9780203806524$

McHugh, M. L. (2012). Interrater reliability: The kappa statistic. Biochemia Medica, 22(3), 276-282. https://www.ncbi.nlm.nih.gov/pmc/articles/PMC3900052/. https://doi.org/10.11613/BM.2012.031.

McNeill, K. L., \& Krajcik, J. (2009). Synergy between teacher practices and curricular scaffolds to support students in using domain specific and domain general knowledge in writing arguments to explain phenomena. The Journal of the Learning Sciences, 18(3), 416-460. https://doi.org/10.1080/10508400903 013488.

McNeill, K. L., \& Krajcik, J. (2011). Supporting grade 5-8 students in constructing explanations in science: The claim, evidence and reasoning framework for talk and writing. New York, NY: Pearson Allyn \& Bacon.
McNeill, K. L., Lizotte, D. J., Krajcik, J., \& Marx, R. W. (2006). Supporting students' construction of scientific explanations by fading scaffolds in instructional materials. The Journal of the Learning Sciences, 15(2), 153-191. https://doi. org/10.1207/s15327809jls1502_1.

National Academies of Sciences, Engineering, and Medicine (2019). Science and engineering for grades 6-12: Investigation and design at the center. Washington, DC: The National Academies Press. https://doi.org/10.17226/2 5216.

National Research Council (1996). National science education standards. Washington DC: National Academy Press.

Bransford, J. D., Brown, A. L., \& Cocking, R. R. (Eds.) (2000). How People Learn: Brain, Mind, Experience, and School. Washington, DC: National Academy Press.

National Research Council (2001). Knowing what students know: The science and design of educational assessment. Committee on the foundations of assessment. In J. Pelligrino, N. Chudowsky, \& R. Glaser (Eds.), Board on testing and assessment, Center for Education. Division of behavioral and social sciences and education. Washington, DC: National Academy Press. https://doi.org/10.1 7226/10019.

National Research Council (2007). Taking science to school: Learning and teaching science in grades K-8. Washington, DC: National Academies Press. https://doi. org/10.17226/11625.

National Research Council (2008). In S. S. Michaels, A. W. Shouse, \& H. A. Schweingruber (Eds.), Ready, set, science! Putting research to work in K-8 science classrooms. Washington D.C.: National Academy Press.

National Research Council (2012a). In H. Quinn, H. Schweingruber, \& T. Keller (Eds. ), A Framework for K-12 science education: Practices, crosscutting concepts, and core ideas. Washington, DC: The National Academies Press.

National Research Council (2012b). Education for life and work: Developing transferable knowledge and skills in the 21st century. Committee on Defining Deeper Learning and 21st Century Skills. In J. W. Pellegrino, \& M. L. Hilton (Eds.), Board on Testing and Assessment and Board on Science Education, Division of Behavioral and Social Sciences and Education. Washington, DC: The National Academies Press. https://doi.org/10.17226/13398

Next Generation Science Standards Lead States (2013). Next generation of science standards: For states, by states. Washington DC: The National Academy Press.

Novak, A. M. (2019). How healthy is our stream for freshwater organisms and how do our actions on land potentially impact the stream and the organisms that live in it? (Teacher and student curriculum materials): https:// learn.concord.org/resources/1025/how-healthy-is-our-stream-for-freshwaterorganisms-and-how-do-our-actions-on-land-potentially-impact-the-stream-a nd-the-organisms-that-live-in-it?. Accessed 21 Nov 2021.

Novak, A. M., Gleason, C., Mahoney, J., \& Krajcik, J. S. (2006). Using extended science investigations to help 7th graders create a classroom culture of scientific practices (chapter 6, 85-97). In R. E. Yager (Ed.), Exemplary science in grades 5-8: Standards-based success stories. NSTA Press.

Novak, A. M., \& Krajcik, J. S. (2019). In A case study of project-based learning of middle school students exploring water quality, M. Moallem, W. Hung, \& N. Dabbagh (Eds.), The Wiley handbook of problem-based learning. WileyBlackwell. https://doi.org/10.1002/9781119173243.ch24.

Novak, A. M., \& Treagust, D. F. (2018). Adjusting claims as new evidence emerges: Do students incorporate new evidence into their scientific explanations? Journal of Research in Science Teaching, 55(4), 526-549. https://doi.org/10.1 002/tea.21429.

Novak, J. D., \& Gowin, D. B. (1984). Learning how to learn. Cambridge University Press. https://doi.org/10.1017/CBO9781139173469.

OECD (2016). PISA 2015 assessment and analytical framework: Science, reading, mathematic and financial literacy. Paris: OECD Publishing. https://doi.org/10.1 787/9789264255425-en.

Quintana, C., Reiser, B. J., Davis, E. A., Krajcik, J., Fretz, E., Duncan, R., ... Soloway, E. (2004). A scaffolding design framework for software to support science inquiry. Journal of the Learning Sciences, 13(3), 337-386. https://doi.org/10.12 07/s15327809jls1303_4.

Roseman, J. E., Linn, M. D., \& Koppal, M. (2008). In Characterizing curriculum coherence, Y. Kali, M. D. Linn, \& J. E. Roseman (Eds.), Designing coherent science education, (pp. 13-36). New York: Teacher College Press.

Rottman, B. M., Gentner, D., \& Goldwater, M. B. (2012). Causal systems categories: Differences in novice and expert categorization of causal phenomena. Cognitive science, 36, 919-932. https://doi.org/10.1111/j.1551-6709.2012.01253.x.

Stapp, W. B., \& Mitchell, M. (1995). Field manual for global low-cost water quality monitoring. Thomson-Shore Printers: A Publication of The Global Rivers Environmental Education Network. 
Tabak, I. (2004). Synergy: A complement to emerging patterns in distributed scaffolding. Journal of the Learning Sciences, 13(3), 305-335. https://doi.org/1 0.1207/s15327809j/s1303_3.

Vallera, F. L., \& Bodzin, A. M. (2020). Integrating STEM with AgLIT (agricultural literacy through innovative technology): The efficacy of a project-based curriculum for upper-primary students. International Journal of Science and Mathematics Education, 18(3), 419-439. https://doi.org/10.1007/s10763-019-09979-y.

Windschitl, M., Thompson, J., \& Braaten,M. (2011). Ambitious pedagogy by novice teachers: Who benefits from tool-supported collaborative inquiry into practice and why? Teachers College Record, 113(7), 1311-2011, https://doi. org/10.1177/016146811111300702.

Wood, D., Bruner, J. S., \& Ross, G. (1976). The role of tutoring in problem solving Journal of Child Psychology and Psychiatry, 17(2), 89-100. https://doi.org/1 0.1111/j.1469-7610.1976.tb00381.x.

Zimmerman, C. (2000). The development of scientific reasoning skills. Developmental review, 20, 99-149. https://doi.org/10.1006/drev.1999.0497 available online at http://www.idealibrary.com.

Vygotsky, L. (1986). Thought and Language. Trans. A. Kozulin. Cambridge: MIT Press. (Original English translation published 1962).

Krajcik, J.S. \& Mun, K. (2014). Promises and Challenges of Using Learning Technologies to Promote Student Learning of Science. In: Lederman, N.G. \& Abell, S.K. (Eds), the Handbook of Research on Science Education. New York, Routledge, pages $337-360$

Nelson, B., \& Hammerman, J. (1996). Reconceptualizing teaching: Moving toward the creation of intellectual communities of students, teachers and teacher education. In M. McLaughlin \& I. Oberman (Eds.), Teacher learning: New policies, new practices (3-21). New York: Teachers College Press.

Novak, A M. (2015). The evolution of 7th graders scientific explanations in project-based classrooms. Unpublished PhD thesis. Curtin University, Perth Australia.

Pellegrino, J. W. \& Hilton M. L. (Eds.). (2012). Education for life and work: Developing transferable knowledge and skills in the 21st century. Committee 011 Defining Deeper Learning and 21 Century Skills. National Research Council of the National Academies. https://doi.org/10.17226/13398.

National Academies of Sciences Engineering and Medicine (2019). Science and Engineering for Grades 6-12: Investigation and Design at the Center. Washington, DC, The National Academies Press.

\section{Publisher's Note}

Springer Nature remains neutral with regard to jurisdictional claims in published maps and institutional affiliations.

\section{Submit your manuscript to a SpringerOpen ${ }^{\circ}$ journal and benefit from:}

- Convenient online submission

- Rigorous peer review

- Open access: articles freely available online

- High visibility within the field

- Retaining the copyright to your article

Submit your next manuscript at $\boldsymbol{\nabla}$ springeropen.com 